\title{
The changing transmission of uncertainty shocks in the
}

\author{
$\mathrm{US}^{1}$ \\ Haroon Mumtaz ${ }^{2} \quad$ Konstantinos Theodoridis ${ }^{3}$
}

January 14, 2016

${ }^{1}$ The views expressed in this paper are those of the authors, and not necessarily those of the Bank of England.

${ }^{2}$ Queen Mary College. Email: h.mumtaz@qmul.ac.uk

${ }^{3}$ Bank of England. Email: Konstantinos.Theodoridis@bankofengland.co.uk 


\begin{abstract}
This paper investigates if the impact of uncertainty shocks on the US economy has changed over time. To this end, we develop an extended Factor Augmented VAR model that simultaneously allows the estimation of a measure of uncertainty and its time-varying impact on a range of variables. We find that the impact of uncertainty shocks on real activity and financial variables has declined systematically over time. In contrast, the response of inflation and the short-term interest rate to this shock has remained fairly stable. Simulations from a non-linear DSGE model suggest that these empirical results are consistent with an increase in the monetary authorities' anti-inflation stance and a 'flattening' of the Phillips curve.

JEL Codes: C15,C32, E32

Key Words: FAVAR, Stochastic Volatility, Uncertainty Shocks, DSGE Model
\end{abstract}




\section{Introduction}

The recent financial crisis and ensuing recession have led to a renewed interest in the possible relationship between economic uncertainty and macroeconomic variables. A number of proxies for uncertainty have been proposed in the recent literature and several papers use VAR based analyses to estimate the impact of uncertainty shocks (see for example Bloom (2009) and Jurado et al. (2013) ). In addition, a growing DSGE based literature has documented the transmission mechanism of these shocks from a theoretical point of view (see for example Fernandez-Villaverde et al. (2011) and Fernández-Villaverde et al. (2011)).

Overall, the empirical literature on this subject provides strong evidence that uncertainty shocks can have a significant adverse impact on the economy. For example, the analysis in Bloom (2009) suggests that a unit increase in uncertainty leads to a $1 \%$ decline in US industrial production and similar results are reported in related papers. However, the estimates reported in these papers are typically based on data that spans the last three or four decades and thus cover periods potentially characterised by changing dynamics, policy regimes and economic shocks.

There has been limited focus on exploring whether the impact of uncertainty shocks has changed over time and identifying the factors that can possibly explain any temporal shifts. Exceptions are Beetsma and Giuliodori (2012) and Choi (2013) who focus on shocks to US stock market volatility and show that the impact of these shocks on real activity has declined over time. However, the results in these papers relate to the impact of stock market volatility rather than the impact of macroeconomic volatility. In addition, and perhaps more importantly, the authors do not provide a theoretical explanation for the identified change in the transmission mechanism. 1

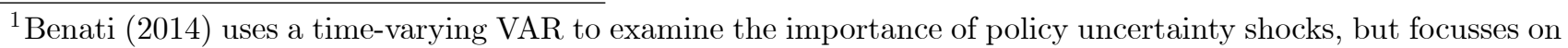
the great recession rather than structural changes over a longer time-period. Caggiano et al. (2014) and Alessandri and Mumtaz (2014) consider the possibility of non-linearities in the impact of uncertainty shocks but do not investigate if the impact may have changed gradually across time. 
This paper attempts to fill these gaps and to introduce a general framework for exploring this issue. First, we propose an extended factor augmented VAR (FAVAR) model that allows the estimation of a measure of uncertainty that encompasses volatility from the real and financial sectors of the economy and is a proxy for macroeconomic uncertainty. The proposed FAVAR allows for time-varying parameters and simultaneously provides an estimate of the time-varying response of macroeconomic variables to shocks to this uncertainty measure, thus allowing the investigation of temporal shifts in a coherent manner. We estimate this model using a comprehensive dataset for the US. Second, we use a non-linear DSGE model to explore the possible reasons behind the identified shifts in impulse responses and thus attempt to provide a structural explanation for the empirical results.

Our results suggest that the impact of uncertainty shocks on measures of real activity, asset prices and indicators of financial conditions has declined systematically over time. For example, the magnitude of the impact of this shock on GDP and the corporate bond spread at the two-year horizon over the current period is estimated to be half of that prevalent during the 1970s and the 1980s. In contrast, the estimated response of inflation and short-term interest rates has been fairly constant over time. We also find a negative co-movement between output and inflation conditional on uncertainty shocks which supports the conclusions reached in Fernández-Villaverde et al. (2011). Simulations from the DSGE model suggest that a possible explanation for these changes may be the structural shifts highlighted in Fernandez-Villaverde and Rubio-Ramirez $(2008)$ - i.e. an increase in the Federal Reserve's anti-inflationary stance and a change in the parameters of the Phillips curve that imply a rise in price stickiness and a fall in indexation to past inflation. An increase in the magnitude of the Taylor rule inflation coefficient implies that inflation responds less to an increase in uncertainty as agents become less concerned about expected inflation. This in-turn allows the monetary authority to reduce interest rates more quickly than otherwise possible to tackle the 
adverse real activity effects of the uncertainty shock and thus reduces the magnitude of the decline in output and asset prices. The simultaneous increase in price stickiness and decrease in the degree of indexation in the model increases the positive response of inflation to the uncertainty shock (as agents hedge against being locked into a contract with an unfavourable price) and thus dampens the initial impact of a rise in the Fed's anti-inflation stance. This implies that the inflation and interest rate response remains fairly constant at short and medium horizons.

The analysis in the paper adds to the literature on uncertainty by systematically investigating how the impact of uncertainty has changed over time and provides a structural explanation for the estimated shifts. The empirical model proposed in the paper builds upon existing VAR and FAVAR models by simultaneously allowing the estimation of time-varying volatility and the timevarying impact of this volatility on the endogenous variables. In addition, the theoretical analysis in the paper contributes to the DSGE applications to this issue by showing how the impact of uncertainty shocks varies with the parameters of various key sectors in the model.

Our results have important implications. Our empirical findings suggest that uncertainty remains a concern for inflation developments. This is particularly important in the current climate where uncertainty has been elevated after the financial crisis and this may go some way in explaining the puzzling persistence of inflation noted by Watson (2014). However, our results suggest that with the decline of the output response to uncertainty, the negative trade-off between inflation and output conditional on uncertainty has declined. This suggests that Fed has additional leeway in dealing with the adverse effects of an uncertainty shock than would be suggested by a fixed coefficient model.

The paper is organised as follows: Sections 2 and 3 introduce the empirical model and discuss the estimation method. The results from the empirical model are presented in Section 4 . We introduce the DSGE model and present the model simulations in Section 5 . 


\section{Empirical model}

The core of the empirical model is the following time-varying parameter vector autoregression (TVP VAR):

$$
Z_{t}=c_{t}+\sum_{j=1}^{P} \beta_{t j} Z_{t-j}+\sum_{j=0}^{J} \gamma_{t j} \ln \lambda_{t-j}+\Omega_{t}^{1 / 2} e_{t}
$$

where $Z_{t}$ is a matrix of endogenous variables that we describe below. The law of motion for the VAR coefficients is given by:

$$
\begin{aligned}
B & =\operatorname{vec}([c ; \beta ; \gamma]) \\
B_{t} & =B_{t-1}+\eta_{t}, \operatorname{VAR}\left(\eta_{t}\right)=Q_{B}
\end{aligned}
$$

As in Primiceri (2005), the covariance matrix of the residuals is defined as:

$$
\Omega_{t}=A_{t}^{-1} H_{t} A_{t}^{-1^{\prime}}
$$

where $A_{t}$ is lower triangular. Each non-zero element of $A_{t}$ evolves as a random walk

$$
a_{t}=a_{t-1}+g_{t}, \operatorname{VAR}\left(g_{t}\right)=G
$$

where $G$ is block diagonal as in Primiceri (2005).

Following Carriero et al. (0), the volatility of the shocks $e_{t}$ is given by: 


$$
\begin{aligned}
H_{t} & =\lambda_{t} S \\
S & =\operatorname{diag}\left(s_{1}, . ., s_{N}\right)
\end{aligned}
$$

The overall volatility evolves as an $\mathrm{AR}(1)$ process:

$$
\ln \lambda_{t}=\alpha+F \ln \lambda_{t-1}+\bar{\eta}_{t}, V A R\left(\bar{\eta}_{t}\right)=Q_{\lambda}
$$

and the diagonal elements of $S$ are scaling factors.

The structure defined by equation 4 suggests that the specification is characterised by two features. First, the model does not distinguish between the common and idiosyncratic component in volatility and $\lambda_{t}$ is a convolution of both components. While separating these unobserved components may be interesting in its own right, it is not directly relevant for our application where the key aim is to estimate overall volatility which, by definition, is a combination of the two components. Secondly equation 4 implies that $\lambda_{t}$ is a simple average of volatility of each shock with equal weight given to each individual volatility. As we show below, this simple scheme produces volatility estimates that are plausible from a historical perspective. Note also that $\lambda_{t}$ is the common volatility of the shocks to equation 1. We interpret this time-varying variance of the unpredictable component of $Z_{t}$ as a measure of uncertainty. Section 4.1 shows that this measure compares favourably to semi-parametric estimates of uncertainty recently suggested in the literature.

The formulation presented in equations 4 and 5 is related to a number of recent empirical contributions. For example, the structure of the stochastic volatility model used above closely 
resembles the formulations used in time-varying VAR models (see Cogley and Sargent (2005) and Primiceri (2005)). Our model differs from these studies in that it allows a direct impact of the volatilities on the level of the endogenous variables. The model proposed above can be thought of as a multivariate extension of the stochastic volatility in mean model proposed in Koopman and Uspensky (2000) and applied in Berument et al. (2009), Kwiatkowski (2010) and Lemoine and Mougin (2010). In addition, our model has similarities with the stochastic volatility models with leverage studied in Asai and McAleer (2009) and the non-linear model proposed in Aruoba et al. (2011). Finally, the model is based on the VAR with stochastic volatility introduced in Mumtaz and Theodoridis (n.d.). While Mumtaz and Theodoridis (n.d.) focus on the impact of volatility associated with the output shock, we focus on an overall measure of uncertainty that incorporates the variance of all shocks in the model. In addition the model proposed above incorporates timevariation, a feature missing from the studies that consider stochastic volatility in mean models.

In our application of this model, we attempt to incorporate a large number of macroeconomic and financial variables in $Z_{t}$. This allows us to account for the possibility of omitted variables and implies that the estimate of $\lambda_{t}$ captures a broad range of economic and financial uncertainty. As is well known in the TVP-VAR literature, the stability of the VAR coefficients at each point in time is difficult to achieve when the number of endogenous variables exceeds 4 (see Koop and Potter (2011)). We deal with this issue by incorporating a factor structure into the model. In particular, we define an observation equation

$$
X_{i t}=\Lambda_{t} Z_{t}+R^{1 / 2} \varepsilon_{i t}
$$

In other words, $Z_{t}$ are assumed to be a set of $K$ unobserved factors that summarise an underlying dataset $X_{i t}$ via the factor loading matrix $\Lambda_{t}$. We allow for time-variation in the factor loadings as 
in Delnegro and Otrok (2005) which evolve as

$$
\Lambda_{t}=\Lambda_{t-1}+\bar{\eta}_{t}, \operatorname{VAR}\left(\bar{\eta}_{t}\right)=Q_{\Lambda}
$$

The idiosyncratic components are defined by $\varepsilon_{i t}$ with a diagonal covariance matrix $R$. As described below, $X_{i t}$ contains key real activity variables, measures of inflation, short and long-term interest rates, money and credit growth and financial variables such as corporate bond spreads, stock market variables and other asset prices. Therefore, the factors $Z_{t}$ contain a large amount of information and as a consequence, the measure of uncertainty $\lambda_{t}$ spans the volatility across the key sectors of the US economy.

\section{Estimation and model specification}

The model defined in equation 1 and 6 is estimated using an MCMC algorithm. In this section we summarise the key steps of the algorithm and provide the details in the technical appendix..$^{2}$ The appendix also presents the details on the prior distributions which are standard. It is worth noting that we follow Cogley and Sargent $(2005)$ in setting the prior for the variance of the shock to the transition equations for the time-varying parameters $\left(Q_{B}\right.$ and $\left.Q_{\Lambda}\right)$. The prior for these covariance matrices is assumed to be inverse Wishart:

$$
\begin{aligned}
& P\left(Q_{B}\right)^{\sim} I W\left(Q_{B, O L S} \times T_{0} \times K, T_{0}\right) \\
& P\left(Q_{\Lambda}\right) \sim I W\left(Q_{\Lambda, O L S} \times T_{0} \times K, T_{0}\right)
\end{aligned}
$$

\footnotetext{
${ }^{2}$ The appendix presents a small Monte-Carlo experiment that shows that the algorithm displays a satisfactory performance.
} 
where $T_{0}=40$ is the length of the training sample and $Q_{B, O L S}$ and $Q_{\Lambda, O L S}$ are the OLS estimate of the coefficient covariances using the training sample where $Z_{t}$ is approximated by principal components. The prior scale matrix is multiplied by the factor $K$ which is set to $3.5 \times 10^{-4}$ as in Cogley and Sargent (2005), but as shown in the sensitivity analysis, the key results also hold for smaller values of $K$. As noted in Bernanke et al. (2005), the FAVAR model is subject to rotational indeterminancy of the factors and factor loadings. Following Bernanke et al. (2005), we impose a normalisation under which the first $K \times K$ block of $\Lambda_{t}$ is fixed to an identity matrix for all time periods.

The MCMC algorithm consists of the following steps:

1. Conditional on a draw for the stochastic volatility $\lambda_{t}$, the factors $Z_{t}$ and the time-varying matrix $A_{t}$, and the variances $S$ and $Q_{B}$ equation (1) represents a VAR model with timevarying coefficients. The algorithm of Carter and Kohn (2004) is used to draw $B_{t}$ from their conditional posterior density and rejection sampling is employed to ensure that the VAR coefficients are stable at each point in time. Conditional on $B_{t}$ the covariance matrix $Q_{B}$ can be drawn from the inverse Wishart (IW) density.

2. Conditional on a draw for the stochastic volatility $Z_{t}, \lambda_{t}, B_{t}$ and $G$ the time-varying elements of $A_{t}$ are drawn equation by equation using the Carter and Kohn (2004) algorithm. Conditional on $a_{t}$, the respective blocks of $G$ are drawn from the IW density.

3. Given $A_{t}$ and $\lambda_{t}$, The elements of $S$ have an inverse Gamma posterior and these parameters can be easily simulated from this distribution.

4. Conditional on $\lambda_{t}$, the constant $\alpha$, autoregressive parameter $F$ and variance $Q_{\lambda}$ can be drawn using standard results for linear regressions. 
5. Conditional on a draw for the factors $Z_{t}, Q_{\Lambda}$ and $R$, the algorithm of Carter and Kohn (2004) is used to draw $\Lambda_{t}$. Conditional on $\Lambda_{t}$ the covariance matrix $Q_{\Lambda}$ can be drawn from the IW density.

6. Conditional on a draw for the factors $Z_{t}$ and the factor loadings $\Lambda_{t}$, standard results for linear regressions can be used to draw from the posterior distribution of the variance of the idiosyncratic components $R$.

7. Conditional on $Z_{t}, B_{t}, A_{t}, S, \alpha, F$ and $Q_{\lambda}$, the stochastic volatility $\lambda_{t}$ is simulated using a date by date independence Metropolis step as described in Cogley and Sargent (2005) and Jacquier et al. (1994) (see also Carlin et al. (1992)).

8. Given the parameters of the observation equation 6 and the transition equation 1 , the Carter and Kohn (2004) algorithm is used to draw from the conditional posterior distribution of the factors $Z_{t}$.

In the benchmark specifications, we use 500,000 replications and base our inference on the last 5,000 replications. The recursive means of the retained draws (see technical appendix) show little fluctuation providing support for convergence of the algorithm.

\subsection{Model specification}

We consider models with 2 to 4 factors and select the model which minimises the Bayesian Deviance Information Criterion (DIC). Note that for models with more than 4 factors it is difficult to ensure stability of the VAR coefficients at each point in time and step 1 of the algorithm described above becomes largely infeasible. Therefore the maximum number of factors is limited to 4 . We show in the sensitivity analysis below that the key results remain the same across models with different number of factors. 
Introduced in Spiegelhalter et al. (2002), the DIC is a generalisation of the Akaike information criterion - it penalises model complexity while rewarding fit to the data. As shown in the appendix, the DIC can be calculated as $D I C=\bar{D}+p_{D}$ where $\bar{D}$ measures goodness of fit and $p_{D}$ approximates model complexity. A model with a lower $D I C$ is preferred. Table 1 shows that the $D I C$ is minimised for the model with 2 factors. Therefore, we select 2 factors in our benchmark model. We show in the sensitivity analysis below that the key results are preserved in a 3 factor model.

\begin{tabular}{ll}
\hline & $D I C$ \\
2 factors & 15447.5 \\
3 factors & 17873.9 \\
4 factors & 20589.5 \\
\hline
\end{tabular}

Table 1: Model Comparison via DIC. Best fit indicated by lowest DIC

Following Cogley and Sargent (2005) and Primiceri (2005) the lag length $P$ is set equal to 2 and we set $j=2$ in the benchmark specification. This choice of $P$ reflects the fact that as the number of lags increase, the stability of the VAR model is adversely affected. Given that we employ quarterly data, we allow the possibility of an impact of $\lambda_{t}$ within a three-month period. We show in the sensitivity analysis below, that the key results are similar when longer lags are employed and when the contemporaneous impact of volatility is set to zero.

\subsection{Data}

The dataset is quarterly and runs from 1950Q1 to 2014Q2. We employ a panel of 39 variables listed in section 1.7 of the technical appendix. These variables include the key aggregates from the dataset of Stock and Watson (2012) that are available from 1950 onwards. We include real activity series such as consumption, investment, GDP, taxes, government spending, employment, unemployment, hours and surveys of economic activity. Data on prices is covered by CPI, consumption and GDP deflator and the producer price index. The dataset includes short-term and long term interest 


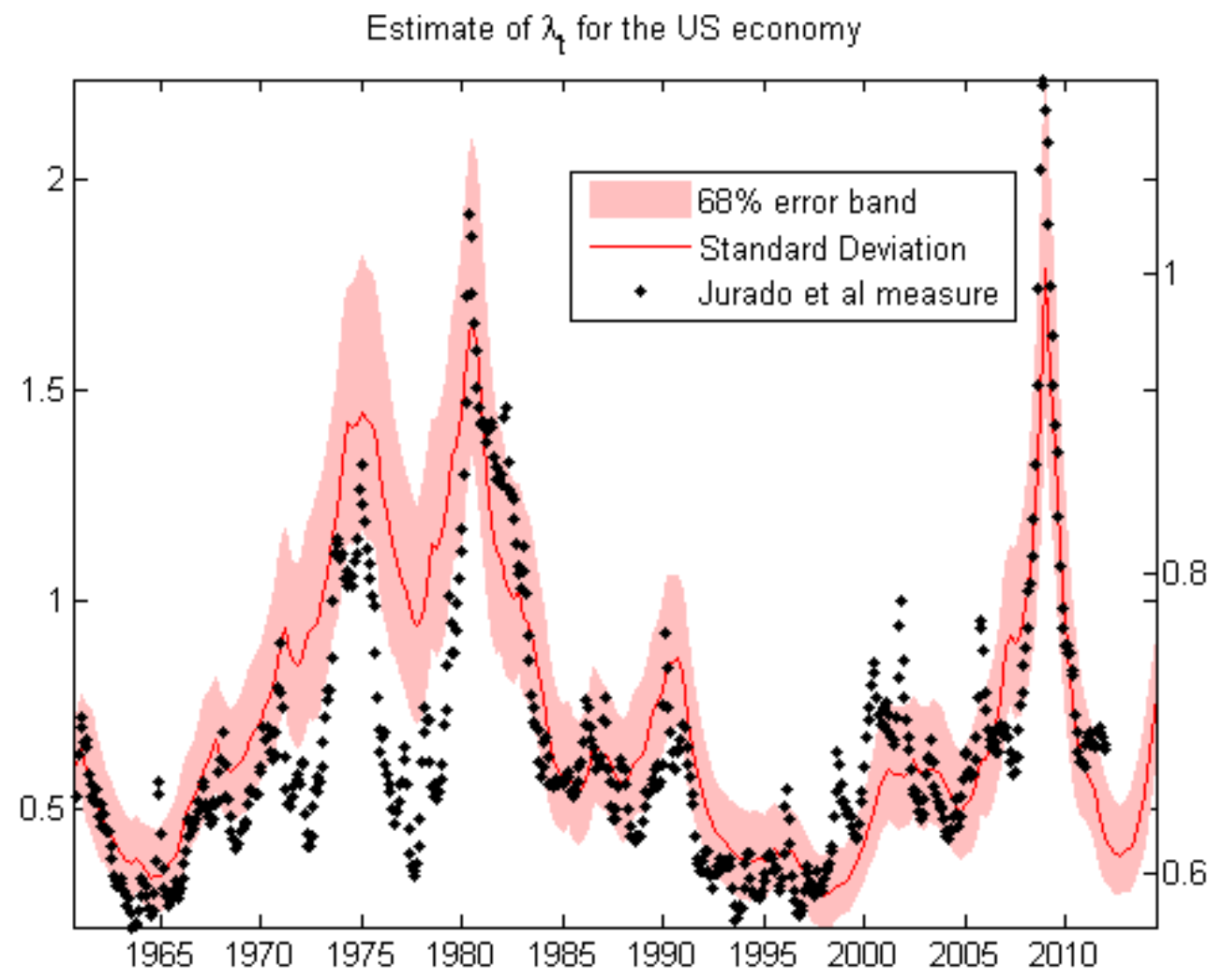

Figure 1: Estimated measure of uncertainty. The non-parametric measure proposed by Jurado et al. (2013) is plotted for comparison.

rates, various corporate bond spreads and series on money and credit growth. Finally, data on stock market variables, commodity prices and exchange rates is included. In summary, the dataset covers the key sectors of the US economy and incorporates a wide range of information.

\section{Empirical results}

\subsection{Uncertainty Measure}

Figure 1 plots the posterior estimate $\lambda_{t}$ for the US. The figure also plots the uncertainty measure recently proposed in Jurado et al. (2013) for comparison. The estimated uncertainty is high during the early and the mid-1970s with a large peak during the early 1980s. The mid-1980s saw the 
onset of the great moderation and $\lambda_{t}$ declined and remained low until the recession during the early years of the last decade. The recent financial crisis saw a substantial increase in uncertainty with the level of $\lambda_{t}$ during 2008/2009 matching the highs in volatility seen during the early 1980s. The figure also plots the semi-parametric measure of uncertainty proposed in Jurado et al. (2013). The measure in Jurado et al. (2013) is estimated as the average of the time-varying volatility of the forecast error of each series in a panel of macroeconomic and financial variables ${ }^{3}$ It is interesting to note that the estimate of $\lambda_{t}$ which is estimated using a model-based approach is highly correlated with this semi-parametric measure of uncertainty. This probably reflects the fact that the model used in this study embodies an idea similar to that employed in Jurado et al. (2013), albeit in a more structured form. In particular, the volatility specification in equations 4 and 5 aims to capture the average volatility in the shocks or the unpredictable component of the factors $Z_{t}$ where these factors represent a summary of real and financial conditions in the US. In the section below we consider how innovations to this measure affect the variables included in our dataset and whether the impulse responses display time-variation.

\footnotetext{
${ }^{3}$ The time-varying volatility is estimated using stochastic volatility models for each series in the panel.
} 


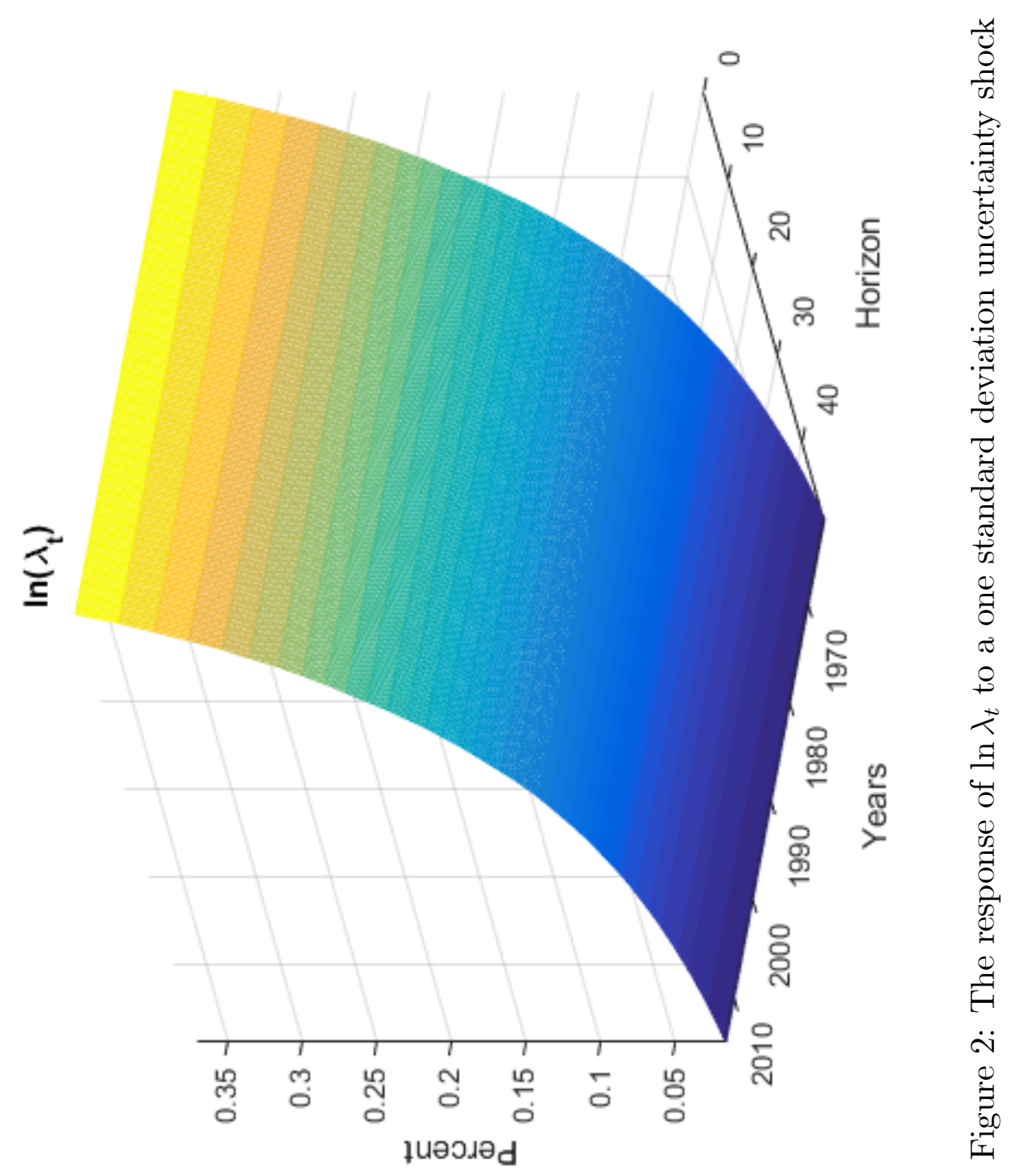




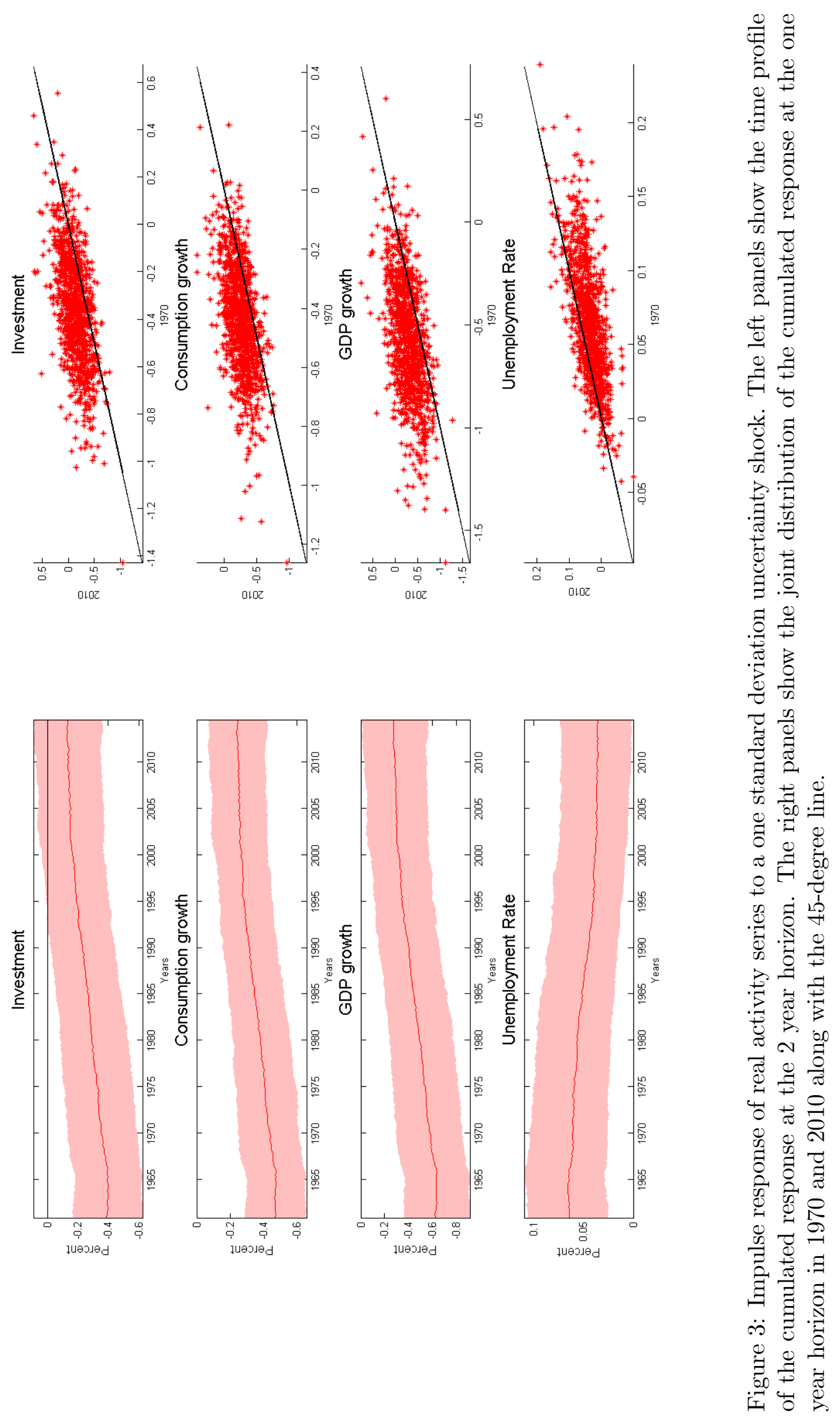




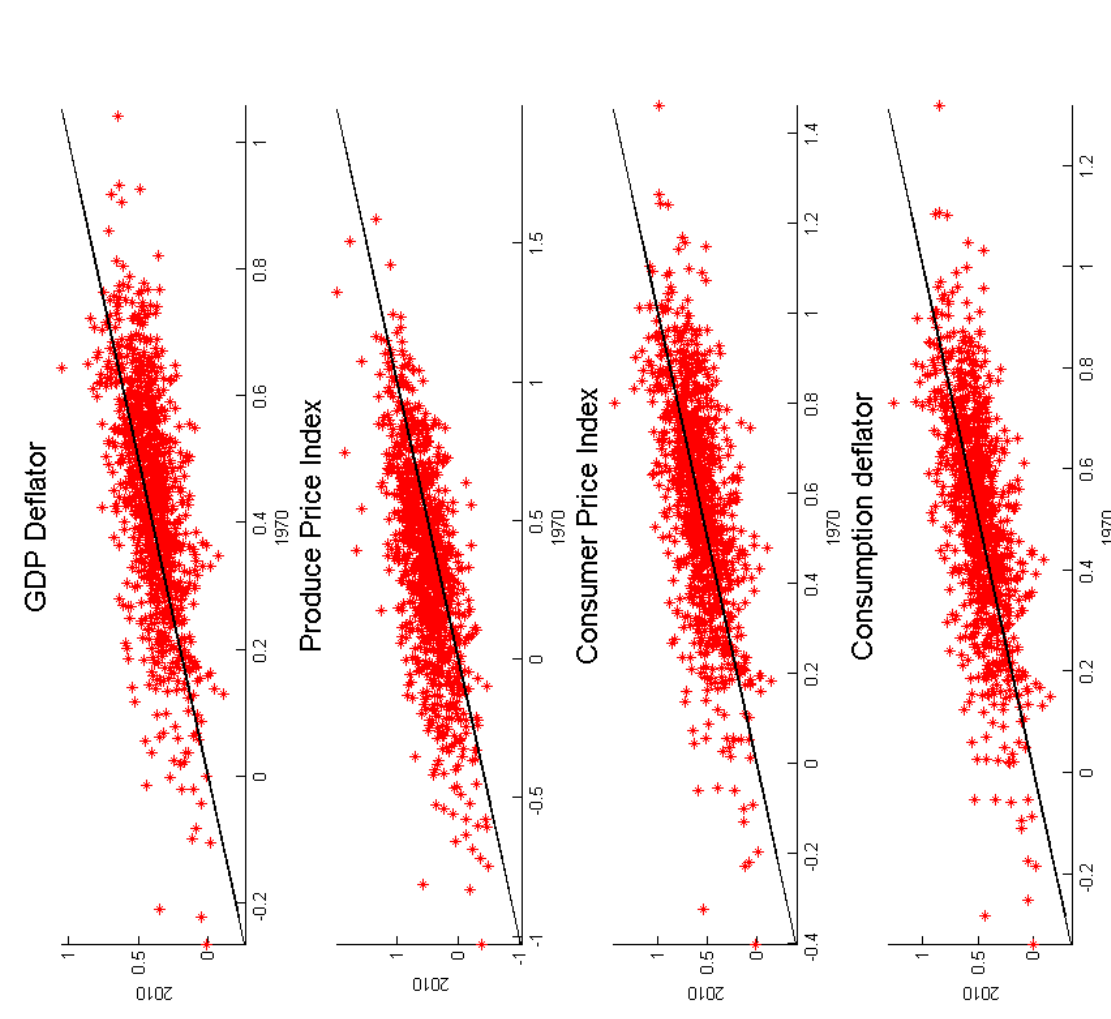

प艹

$\begin{array}{ll}0 & 0 \\ 0 & 0 \\ 0 & 0 \\ 0 & 0 \\ 0 & 0\end{array}$

。ำ

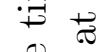

\$

合

告

苗

芯节

E

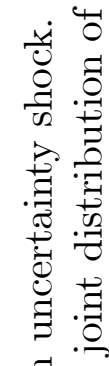

.

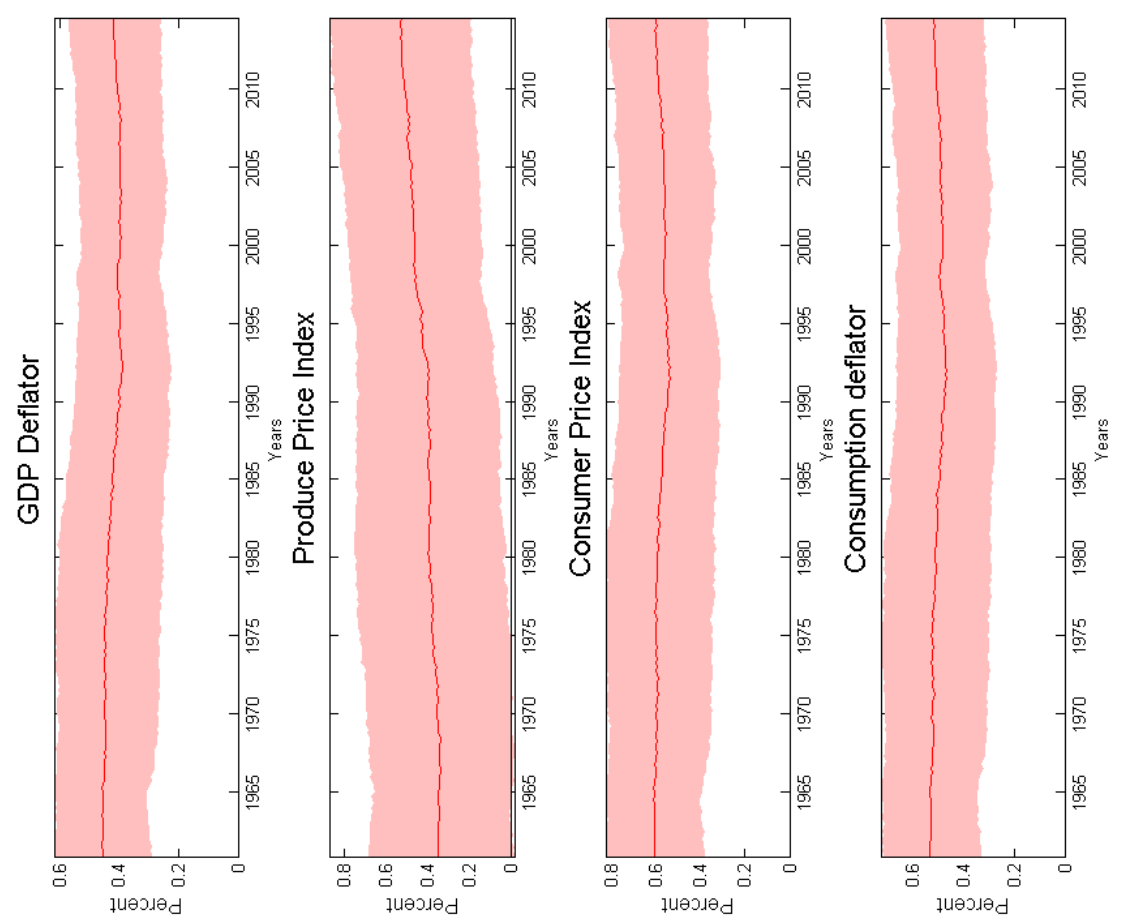

造造

苛

要

क

ช 8

다 50

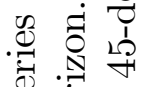

究

营离声

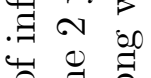

Ч

屯ै त

ํㅡㄴ

o

릴요

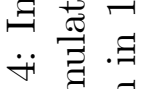

○

我 

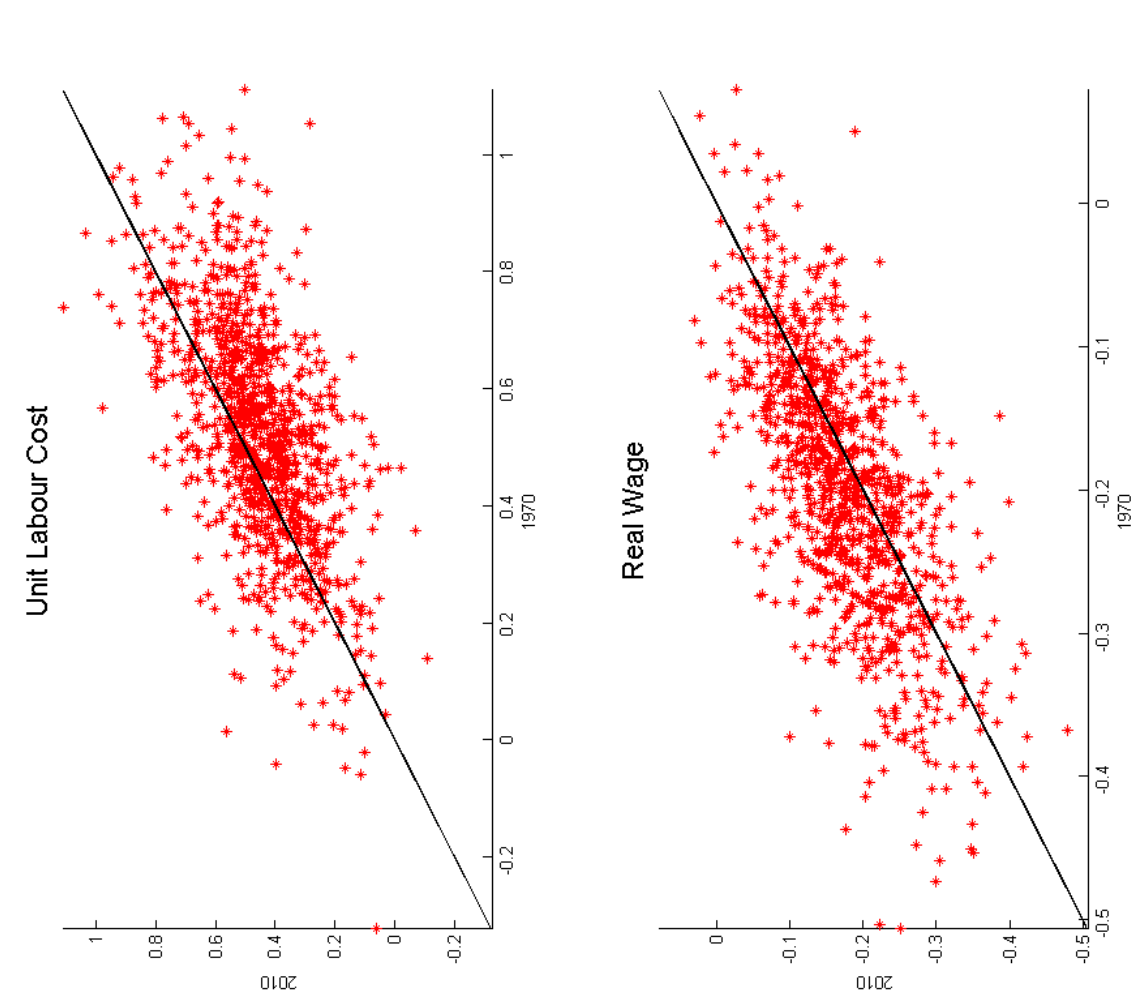

फ

릴

है

임

孚

30

क्ष है

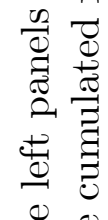

욯

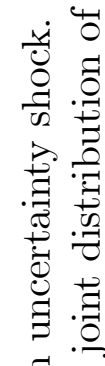

윰
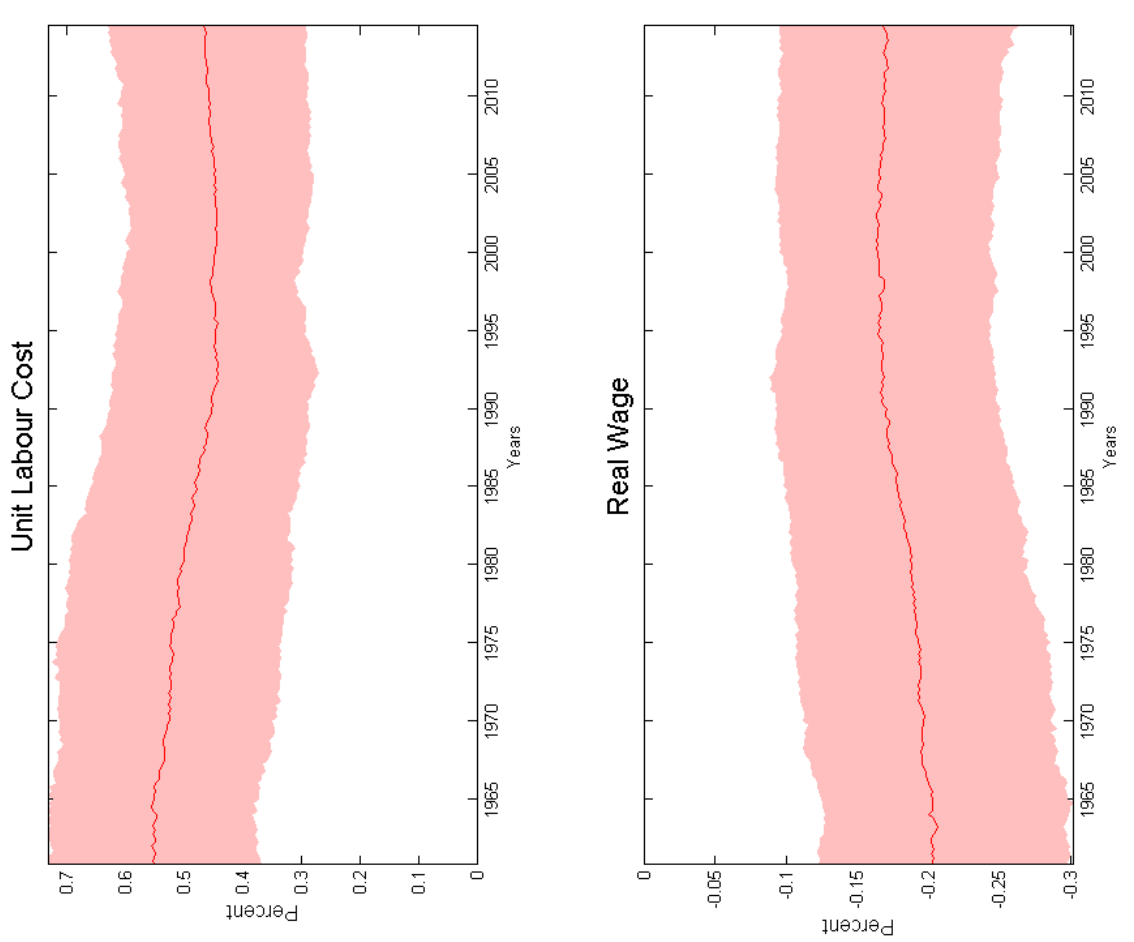

雚

?.

त्త్ర

สี

0

范 $:$

ช ญ

어

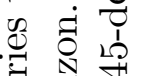

क

当离声

ชิ $N$

प웡

舫

융

Ð స్ర

की छै

苟 D

폴

○

的告 

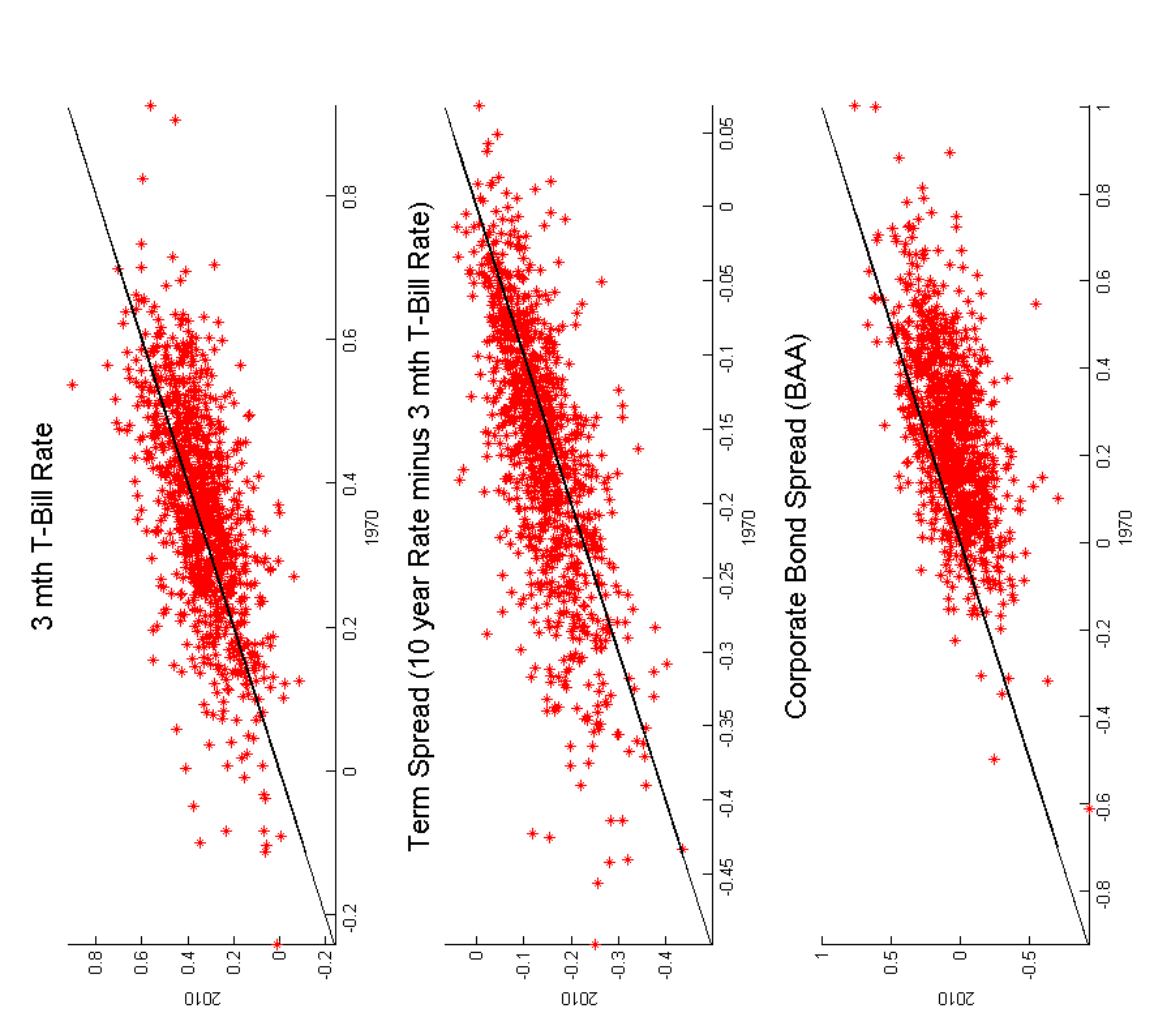

륨ํㅠ

苛范

ఫ

官矛

n

气ี

武

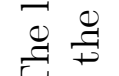

F

剀

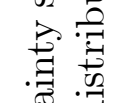

苞.

도웜

离
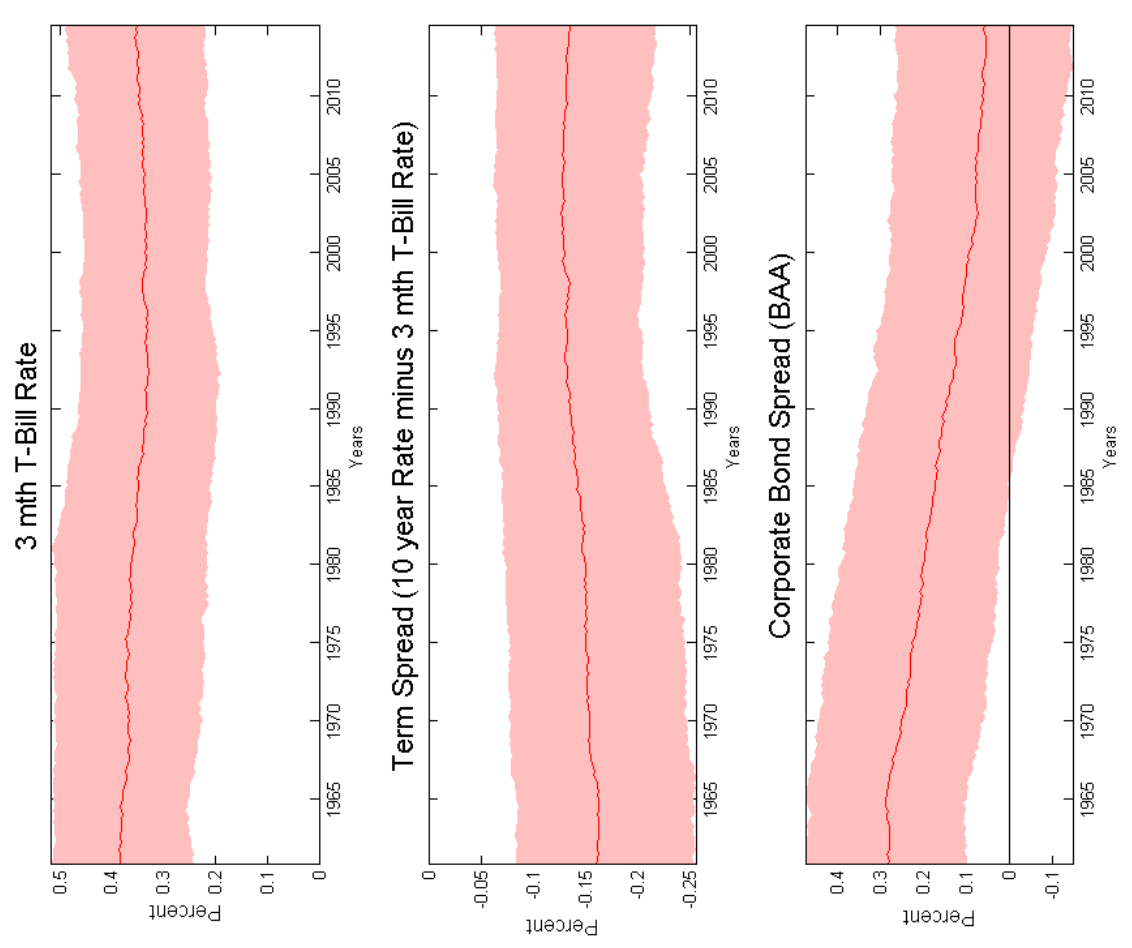

률

焉声导

ఫ.

० 00

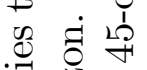

灾

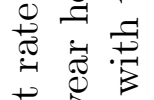

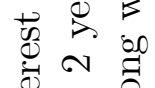

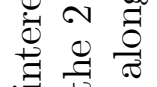

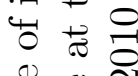

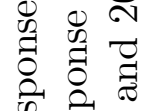

矛部

क ठ

忌芯

○

0 의

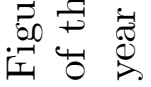



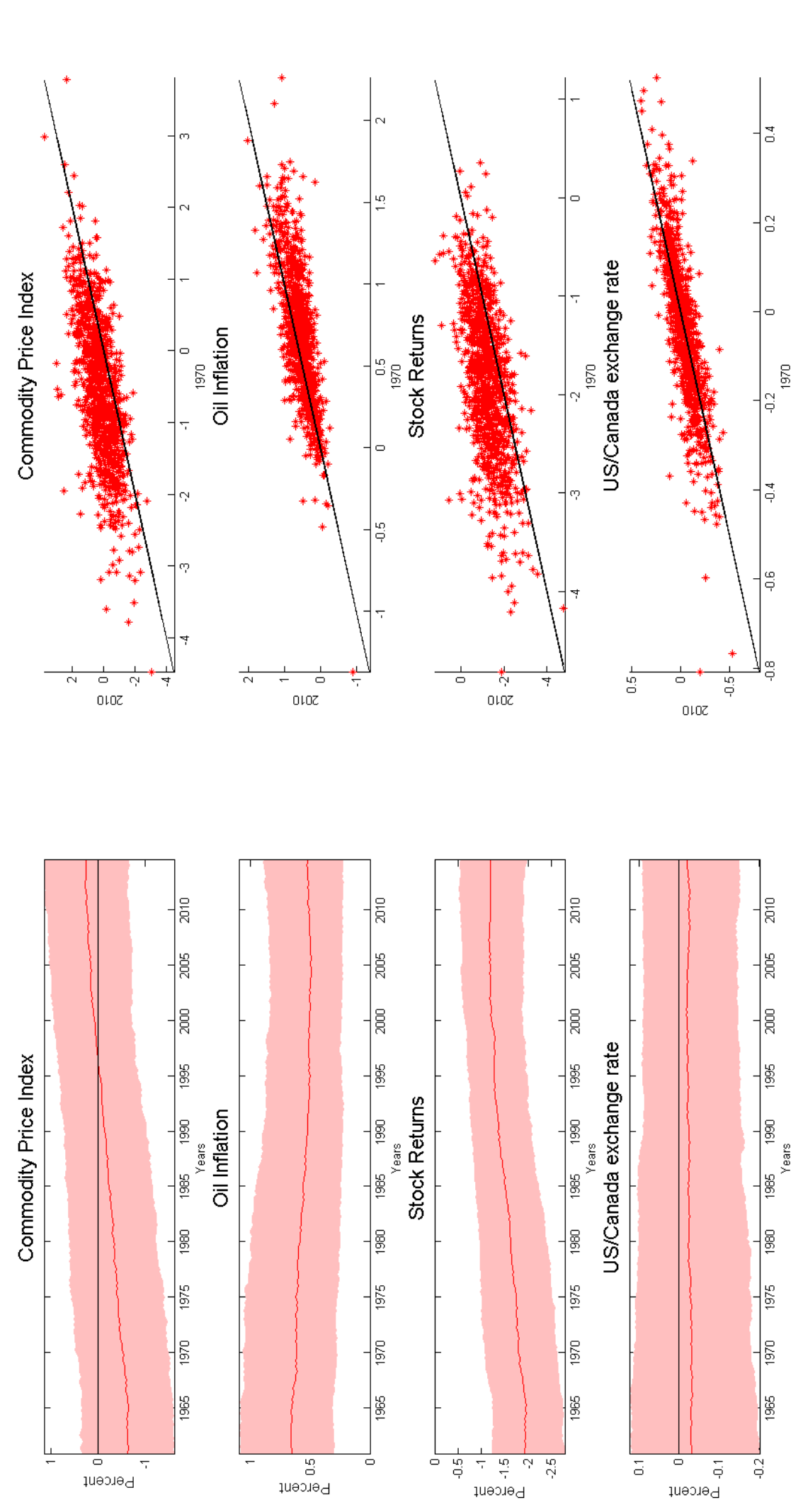

윰요

2

要

क्ष

官

क

芯

苟

욤

F

苍

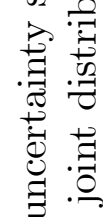

훙

.

范

茜范

a .0

\%

๙

용

造

进

苛

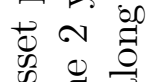

क

낭 눙

范

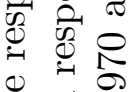

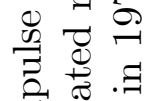

高营

등

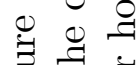

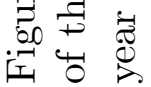




\subsection{Impulse response to uncertainty shocks}

In this section we report the response of key variables to a shock to uncertainty calibrated to equal $Q_{\lambda}^{1 / 2}$, i.e. one standard deviation, in each quarter. Figure 2 shows that this shock increases the volatility $\ln \lambda_{t}$ by around 0.4 at each point in time. Figure 3 shows the response of real activity to this shock. The left panels of the figure show the cumulated response at the two year horizon. The right panels display the joint distribution of this response in the early and later part of the sample and compare this with the 45-degree line. A systematic difference across time can be detected if the points on the scatter plot deviate from the 45 -degree line ${ }^{4}$

Figure 3 shows that the response of real activity to uncertainty has declined over time. Consider the response of GDP growth. GDP growth fell by $0.5 \%-0.6 \%$ in response to the uncertainty shock over the 1970s and the early 1980s. In contrast, after the mid-1990s, the decline in this variable in response to the uncertainty shock is closer to $0.3 \%$. The right panel shows that this decline in the magnitude of the response is systematic-the points in the joint distribution mostly lie above the 45-degree line suggesting that the response in 2010 was less negative than in the earlier period. Similarly, the response of consumption growth, investment and the unemployment rate shows a systematic decline after the mid-1980s.

Figure 4 shows the response of a number of inflation series to the uncertainty shock. Note that the response of inflation to the uncertainty shock is estimated to be positive and thus supports the existence of pricing bias channel postulated in Fernández-Villaverde et al. (2011). In contrast to the real activity responses, there is little evidence of any systematic decline in the magnitude of the response. The estimated joint distribution in 1970 and 2010 is clustered evenly around the 45-degree line. Similarly figure 5 shows that a similar conclusion holds for unit labour costs and

\footnotetext{
${ }^{4}$ We focus on the two year horizon for simplicity. The full three-dimensional plots of the time-varying impulse responses can be found in the appendix to the paper.
} 
earnings-the response of these variables is fairly stable across time.

Figure 6 plots the time-varying response of the short term interest rate and spreads. While the response of the short term rate and the term spread is fairly constant over time, there appears to be a systematic decline in the response of the corporate bond spread to this shock with the cumulated response falling from about $0.3 \%$ in the early part of the sample to around $0.1 \%$ over the last decade. The bottom right panel provides some evidence that the change in this response is systematic.

The time-varying response of various asset prices to this shock is shown in figure 7. The response of stock returns at the 2 year horizon was about $-2 \%$ during the 1970 s and the 1980 s. In contrast, stock returns declined by about $1 \%$ in response to the uncertainty shock after 2000 . Similarly, the response of the commodity price index has declined over time. Note, however, that the error bands are wide for this response over the entire sample.

In summary, the estimates suggest that the response of real activity indicators (GDP growth, consumption growth, investment and unemployment) and some financial variables (corporate spread and stock returns) to uncertainty shocks has declined over time. In contrast, the response of inflation and the short-term interest rate to this shock is estimated to have been fairly stable.

We show in section 1.6 of the technical appendix that these conclusions are robust to various changes in the specification of the empirical model. In particular, these results survive if the lag structure of the model is changed-we estimate versions of the model where (a) four lags of $\lambda_{t}$ are allowed to affect the endogenous variables and (b) where the assumption that uncertainty has a contemporaneous effect on the endogenous variables is relaxed. In both cases, we find that the response of real activity and financial variables declines while the response of inflation and the short-term rate is stable. Similarly, expanding the number of factors to 3 has little impact on these conclusions. In addition, the impulse responses remain unchanged if the volatility of idiosyncratic 
shocks $\left(\varepsilon_{i t}\right.$ in equation 6 ) is assumed to be time-varying. Finally, we employ a tighter prior on the parameters governing the degree of time-variation in the coefficients $\left(Q_{B}\right.$ and $\left.Q_{\lambda}\right)$ and find that the conclusions reached above are largely unaffected.

The sensitivity analysis, therefore, supports the following main conclusion: There is evidence that the response of real activity and some financial indicators to the uncertainty shock has declined over time. In contrast, the response of inflation and interest rates to this shock has remained largely stable. We now turn to a DSGE model in order to explore the possible reasons behind the estimated temporal change in the impact of uncertainty shocks.

\section{Explaining the results: a DSGE model}

\subsection{Summary of the model}

The model used in this study is the one developed by Fernandez-Villaverde and Rubio-Ramirez (2008) (which in turn is a close relative to those developed by Christiano et al. (2005) and Smets and Wouters (2007)). Following Christiano et al. (2014), we augmented this model with Bernanke et al. (1999) type financial frictions. Briefly, the model features risk-averse consumers who supply labour to differentiated and sticky wage labour unions. There are risk-neutral entrepreneurs who borrow from perfectly competitive banks, build capital goods that they rent to the imperfectly competitive (sticky price) producers of intermediate goods. Entrepreneurs, who are monitored by the banks, are subject to an idiosyncratic productivity shock. For an idiosyncratic shock below a threshold value, they declare bankruptcy and have everything taken from them. To prevent entrepreneurs from accumulating net-worth up to the point where the financial frictions become irrelevant, we assume that a fraction of them dies and the complementary fraction is born. There are perfectly competitive retailers selling the aggregated intermediate goods as a composite final 
good to the consumers. The final good is transformed to consumption and investment goods via linear technologies. However, the latter is subject to a non-stationary productivity shock. This stochastic trend is in addition to a labour augmented non-stationary shock. Government in this model runs a balanced budget in every period and the central bank sets monetary policy according to a Taylor-like rule. The model features a number of real (monopolistic competition, investment adjustment cost, capital utilisation and habits in consumption and asymmetric information between borrowers and lenders) and nominal (price and wage stickiness) frictions. In addition to the two non-stationary shocks, this economy is also subject to a preference, labour disutility and interest rate policy stationary shocks. These shocks are conditionally heteroscedastic and (consistently with the empirical model) subject to a common stochastic volatility shock. Note that we assume that this shock represents the uncertainty shock in the DSGE model.

The parametrization of the model is based on Fernandez-Villaverde and Rubio-Ramirez (2008) and Christiano et al. (2014). The model is solved using a third order perturbation and generalised impulse responses are computed. Details of model equations, the solution algorithm and impulse response calculation are provided in section 2 of the technical appendix.

The blue lines in figure 8 show the response to an uncertainty shock under the benchmark calibration of the model. We see in these simulations that as the uncertainty rises, agents respond by lowering (consumption and investment) demand and increasing (precautionary) savings. Furthermore, agents expand their labour supply (see (Basu and Bundick, 2011)) pushing wages down and this offsets the increase in the rental rate of capital causing marginal cost to fall. Although, the marginal cost decreases, inflation rises because forward looking firms bias their pricing decision upwards in order to avoid supplying goods when demand and costs are high. Monetary authorities set policy according to a Taylor type rule and this constrains their ability to expand policy significantly and mitigate the adverse consequences from the uncertainty shock. This re-enforces 
agents' precautionary saving motives inducing a further reduction on demand. This in turn results in a fall in net worth and a rise in credit spreads.

\subsection{DSGE interpretation of the empirical results}

The empirical evidence suggests that the effect from an increase in aggregate uncertainty on measures of real activity, asset prices and indicators of financial conditions has declined systematically over time. In contrast, the estimated response of inflation and short-term interest rates has been fairly constant. In this section we use the DSGE model discussed earlier to identify what 'constellation' of structural parameters could be consistent with this pattern. We do this by considering a set of simulations under which key parameters in the model are changed and examine if the resulting shift in the response to uncertainty shocks matches the temporal pattern of impulse responses estimated using the FAVAR model. This approach is similar in spirit to estimating model parameters by matching empirical and theoretical impulse responses, albeit less formal. We prefer this approach for two reasons. First, the non-linearity of the DSGE model implies that the computation of the (generalised) impulse responses is time-consuming and this hinders the use of numerical optimisation to minimise the distance between responses. Secondly, as argued forcefully in Canova and Sala (2009), weak or partial identification is a major issue in simulated method of moments and may lead to misleading results.

There are several existing DSGE studies that offer robust evidence regarding changes in the policy reaction function (see Lubik and Schorfheide (2004) and Davig and Leeper (2007) among others) and changes in the price and wage setting behavior of firms and households, respectively (see Fernandez-Villaverde and Rubio-Ramirez (2008) and Hofmann et al. (2012) among others). It seems, therefore, natural to initiate our investigation from those parameters and ask whether they could also explain changes in the pattern of uncertainty responses predicted by the empirical 
model. In addition we also consider the possibility that the economy has been subject to a process of financial liberalisation.

The simulations make the simplifying assumption that agents do not take the structural break in model parameters into account when forming expectations and the model is solved separately before and after the parameter change. There are, however, a number of reasons that suggest that these parameter changes may be thought of as permanent shifts that were not expected by agents and, as a consequence, our simplifying assumption may be reasonable in the present context.5 First, the parameter shifts considered in the experiments below have been shown to be highly persistent by previous studies. For example, the changes in the policy reaction function and price and wage setting behaviour estimated by Fernandez-Villaverde and Rubio-Ramirez (2008) occur after the early 1980s and appear to last until the end of their sample in 2000Q4. Second, studies such as Benati and Mumtaz (2007) document a sharp increase in volatility of shocks to monetary policy and output and inflation innovations during the early 1980s with the variance declining after the middle of this decade. For monetary policy, this partly reflected uncertainty regarding the Federal Reserve's money growth targets as this period was associated with a breakdown in the relationship between monetary aggregates and the real economy (see Friedman (2005)). As a consequence, the Federal Reserve shifted its focus from narrow to broad money and finally to short term interest rates as its monetary policy instrument. Given the numerous operational changes over this period, it is perhaps reasonable to assume that agents were, to a degree, uncertain about the structural shifts taking place and that these shifts were not fully expected. A similar argument can be made for changes in price and wage setting behaviour which were potentially affected by numerous factors ranging from commodity price fluctuations to globalisation. Given these two features, a simulation methodology that assumes independent expectation formation in

\footnotetext{
${ }^{5}$ We thank an anonymous referee for pointing this out.
} 
each assumed regime may provide a reasonable approximation.

\subsubsection{Hawkish Central Banker}

We start by considering what happens when monetary policy authorities increase the weight placed on inflation (Figure 8). The dashed red line represents the scenario under which the policymaker's reaction coefficient to inflation $\left(\gamma_{\pi}\right)$ in the monetary policy rule increases $-\gamma_{\pi}$ rises from 1.01 to 1.5. The exercise suggests that the economic effects of an exogenous increase in uncertainty diminish as the policymaker fights inflation aggressively. When $\gamma_{\pi}$ rises and authorities react strongly to inflation, future inflation is expected to be on target. This reduces firms' concerns about expected inflation and makes them less forward looking. In other words, the pricing bias decreases and the link between inflation and marginal cost is renewed. In this case authorities are able to cut the policy rate by more and for a longer period, which helps them to address the adverse effects from elevated uncertainty. The resulting amelioration in the fall in investment improves the entrepreneurs' leverage position and the increase in the credit spread is smaller.

The changes in the impulse responses predicted by the rise in $\gamma_{\pi}$ go in the direction of the empirical results-the fall in the magnitude of the real activity and credit spread response is consistent with the estimates from the FAVAR. Note, however, that unlike the empirical estimates, the model simulations also predicts a decline in the response of inflation and the policy rate at all horizons. 

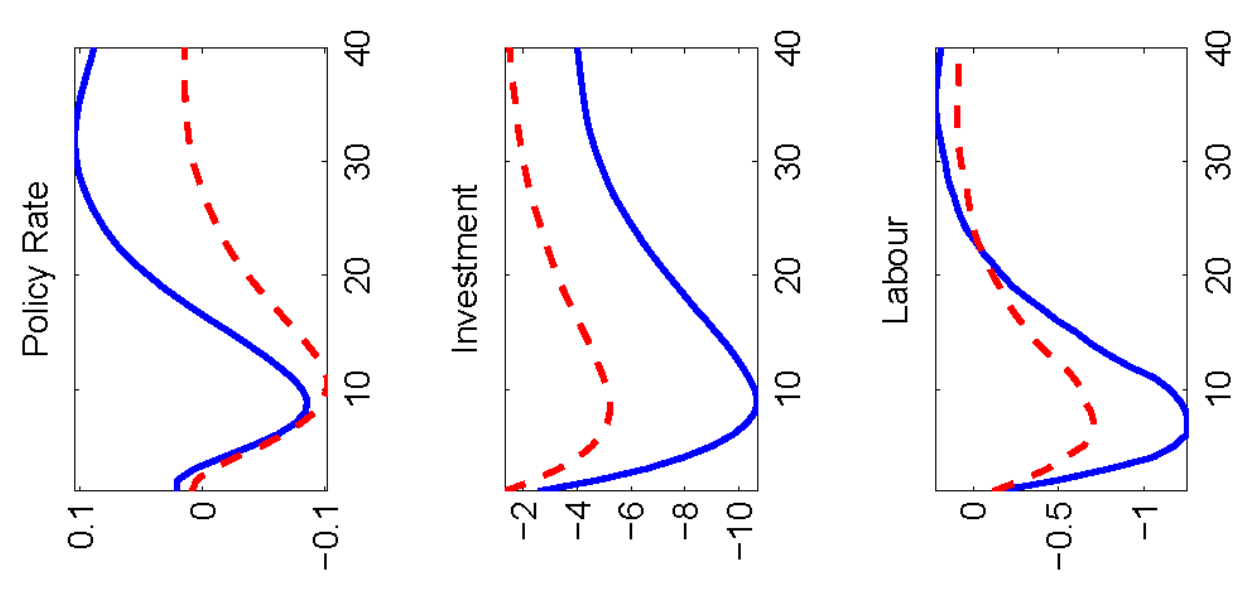

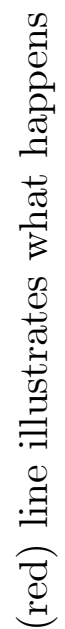
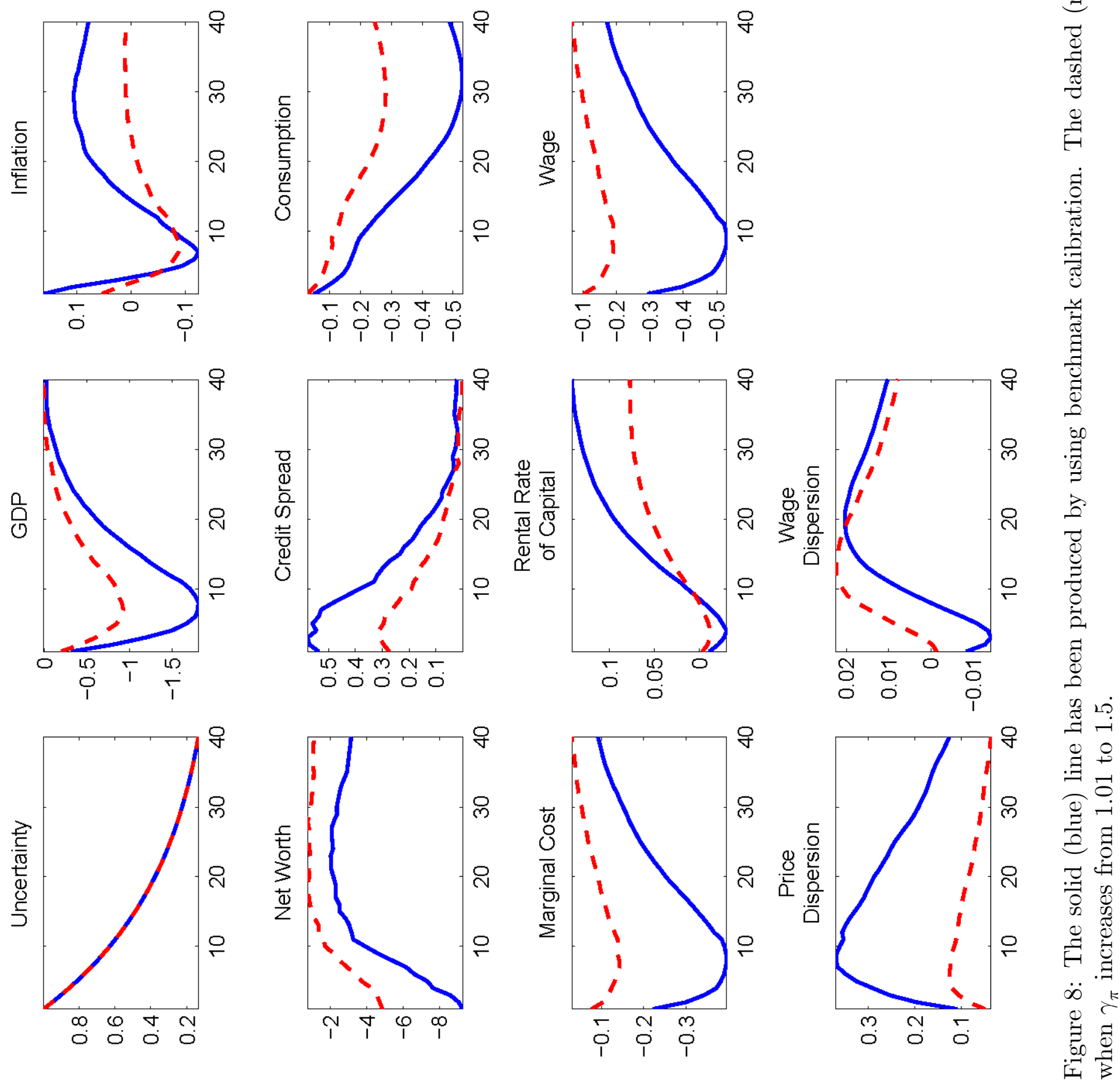

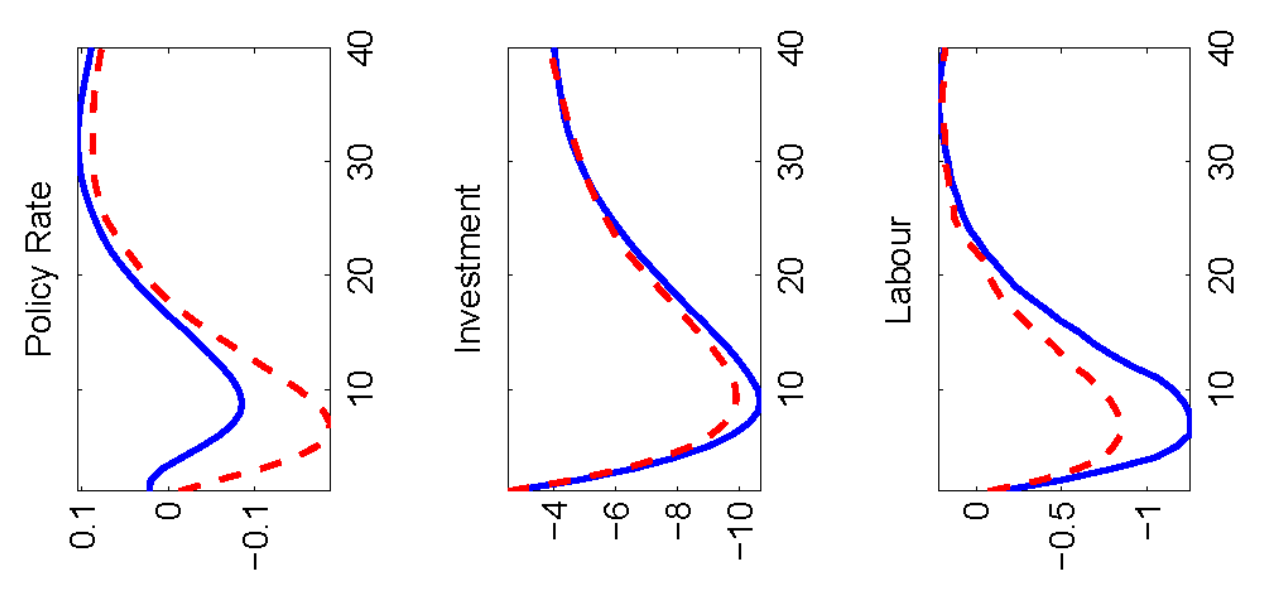

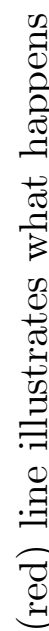
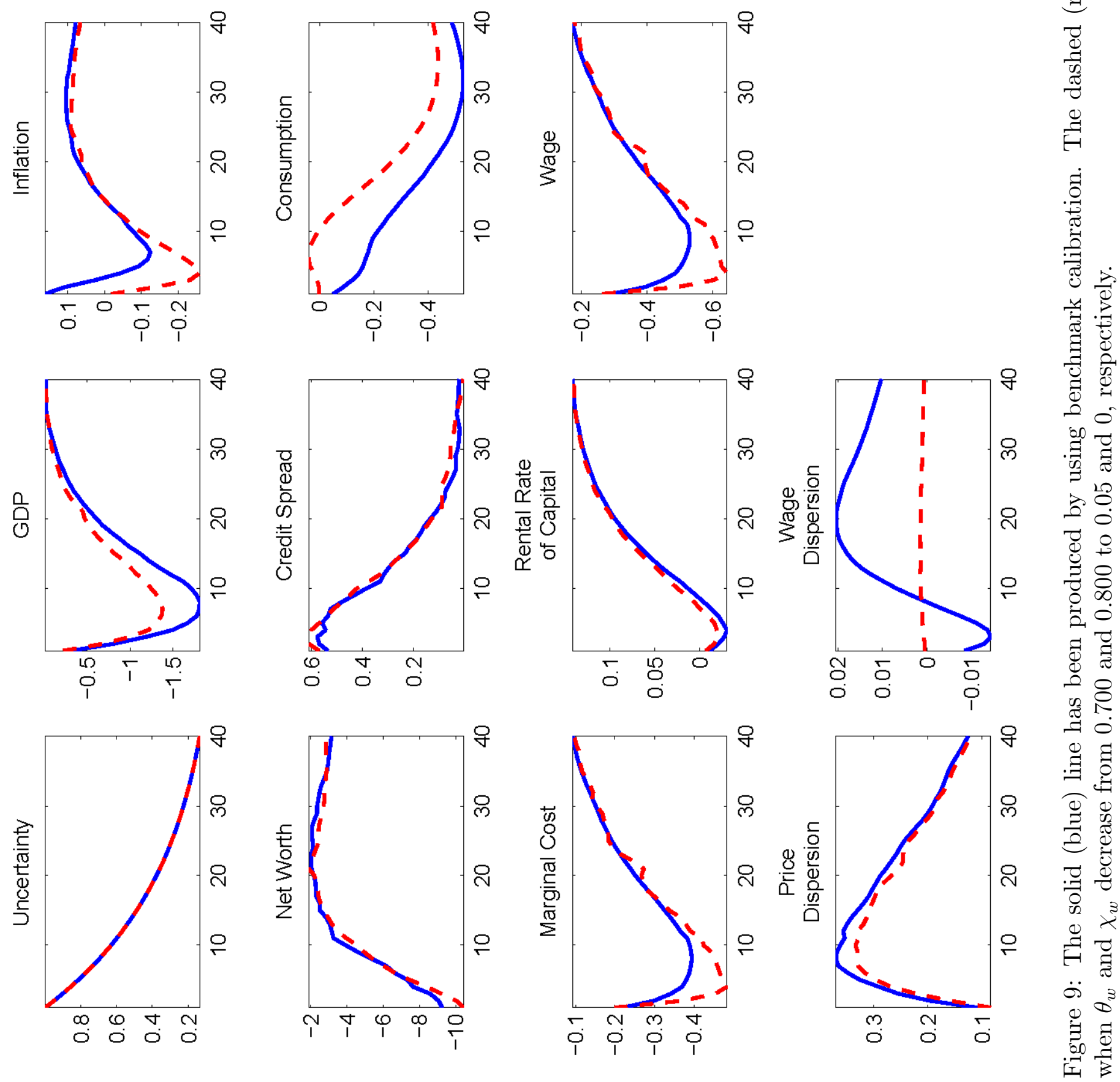

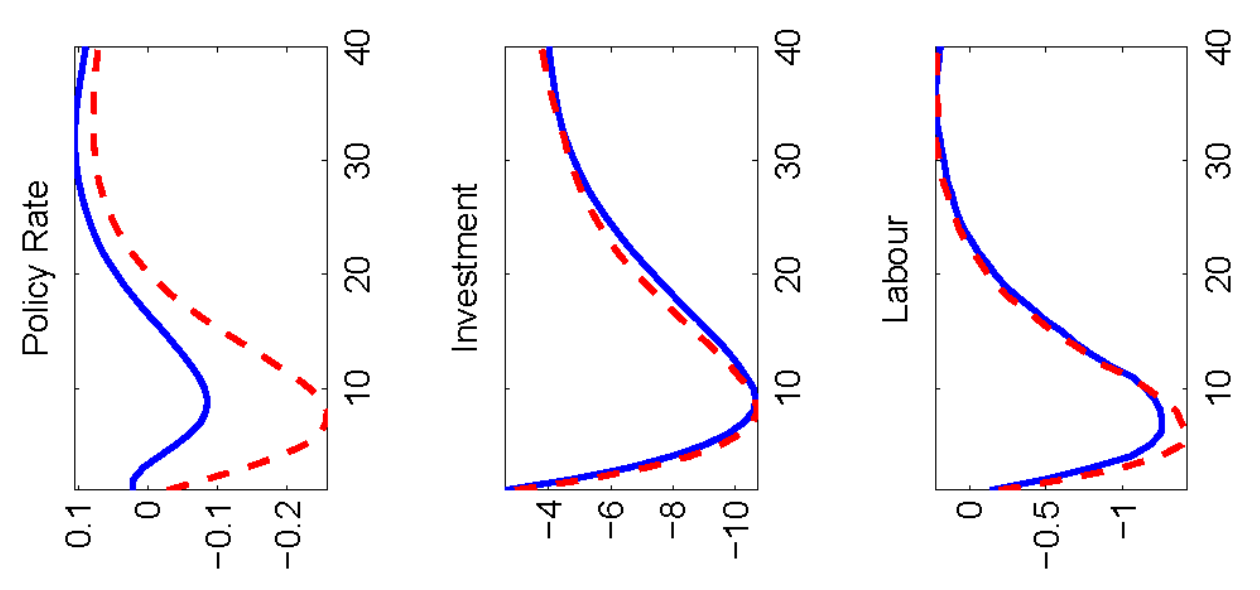

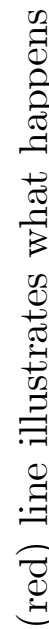
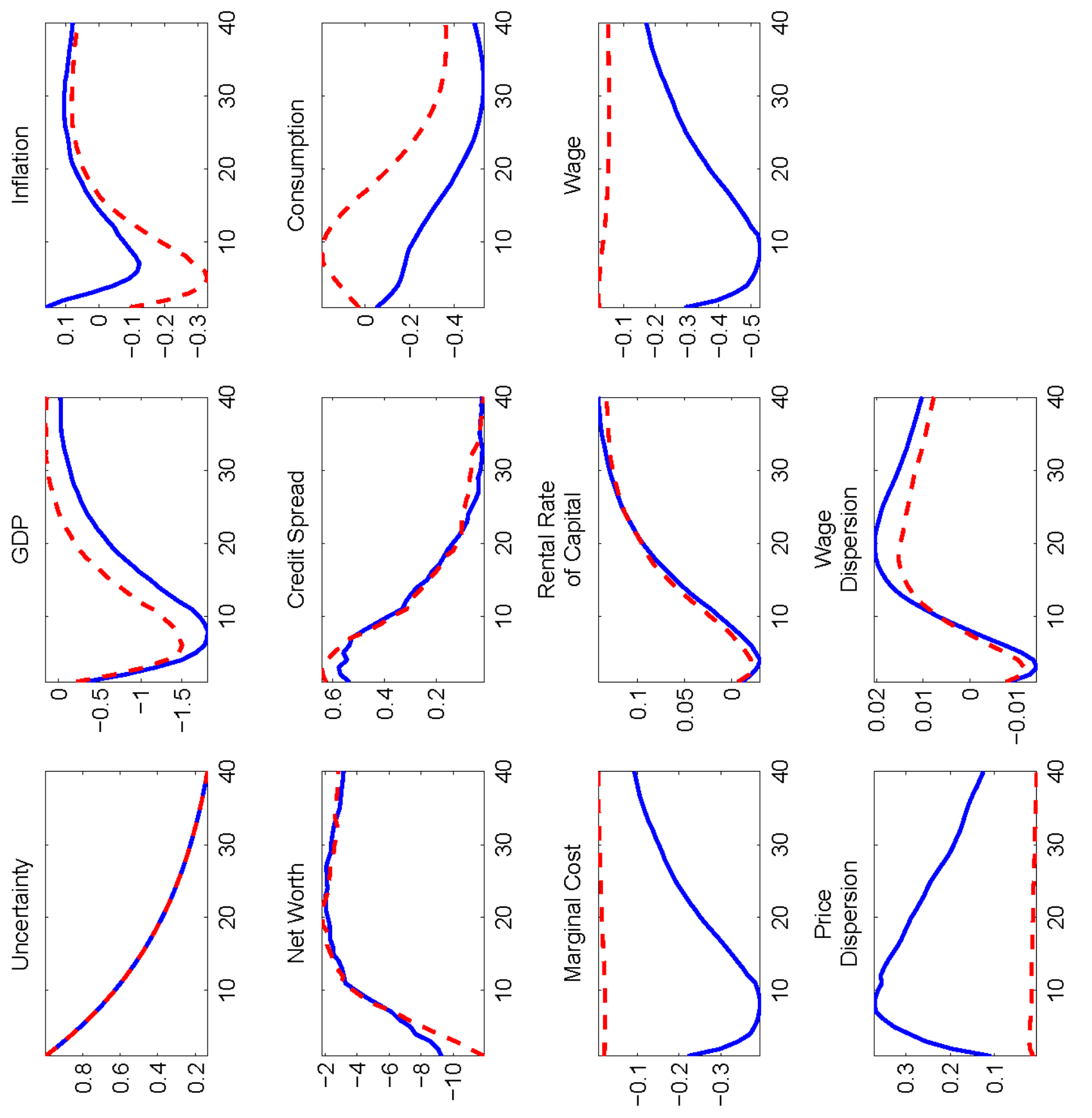

गु 

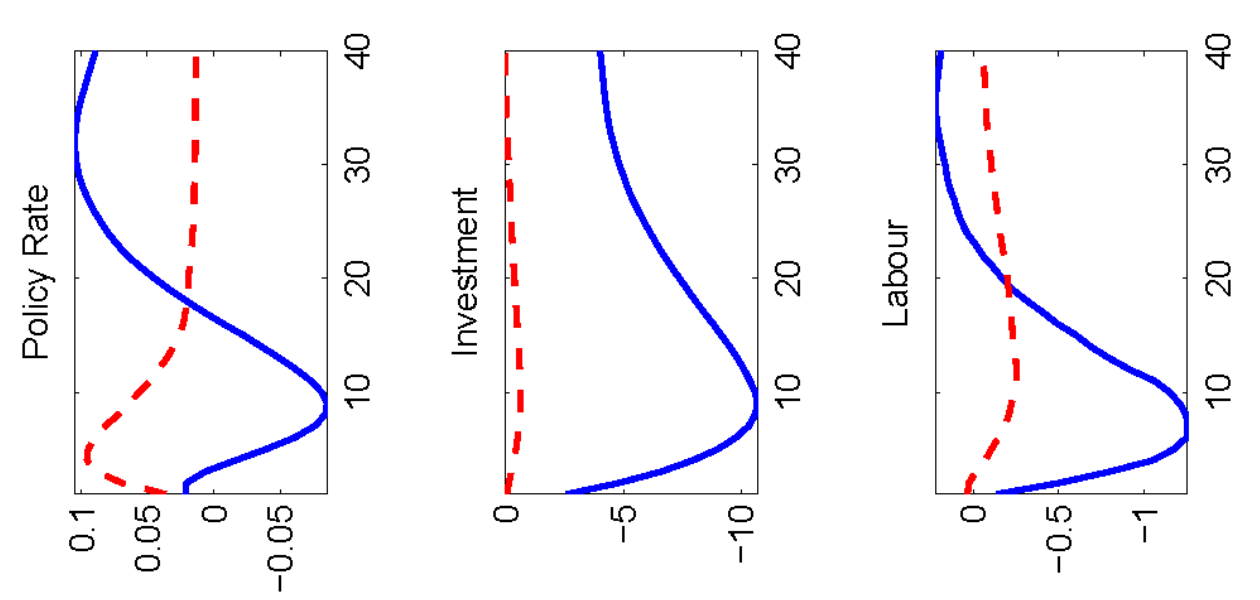

0
0
0
$\frac{\pi}{3}$
$\frac{\pi}{3}$
$\frac{\pi}{3}$
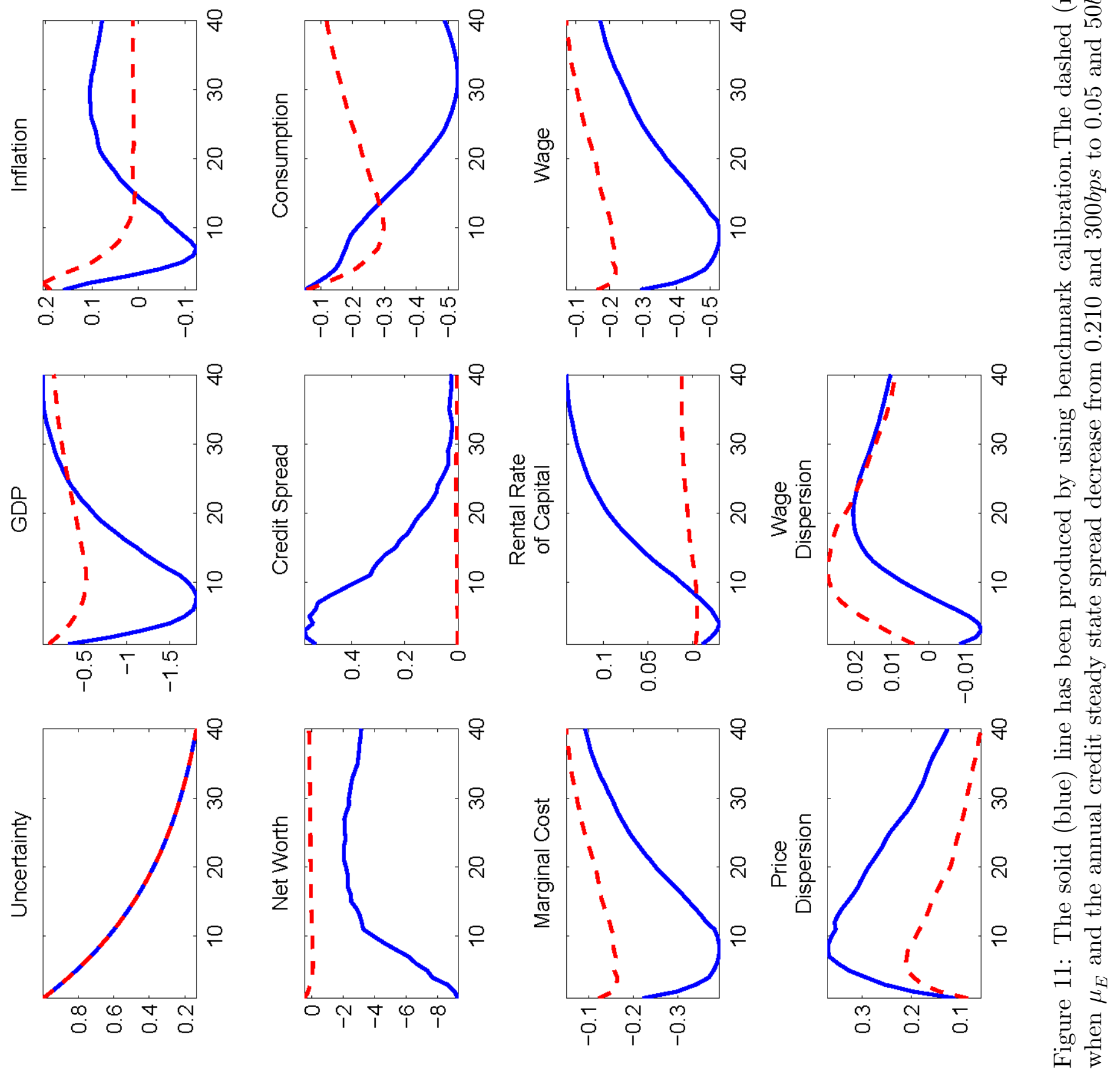

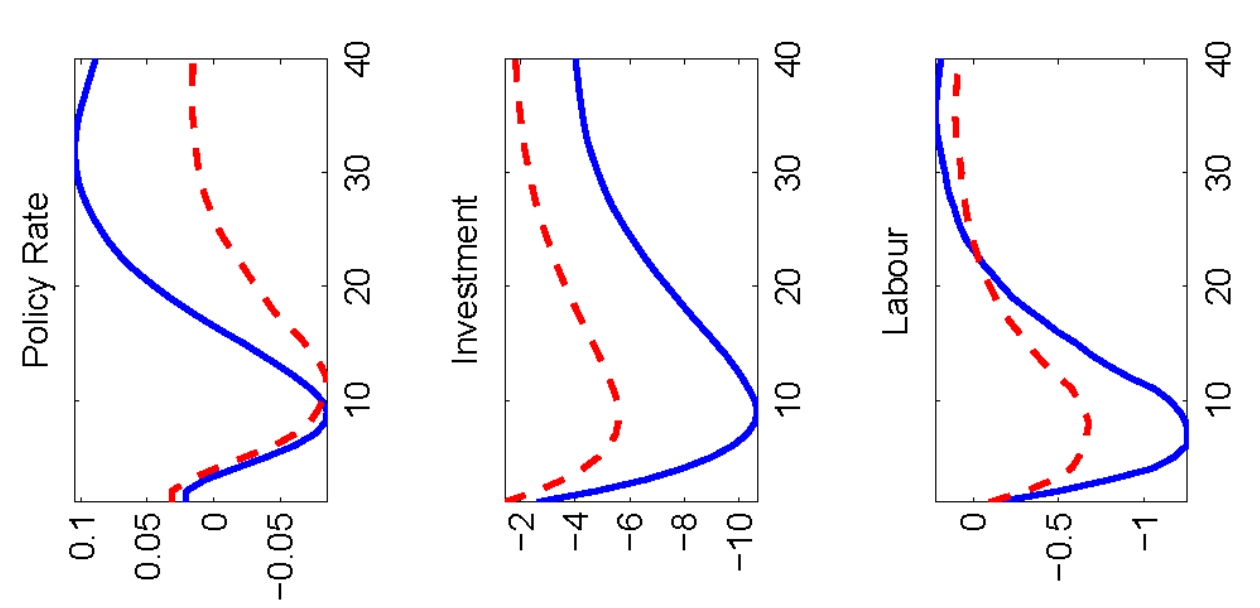

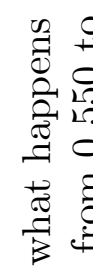
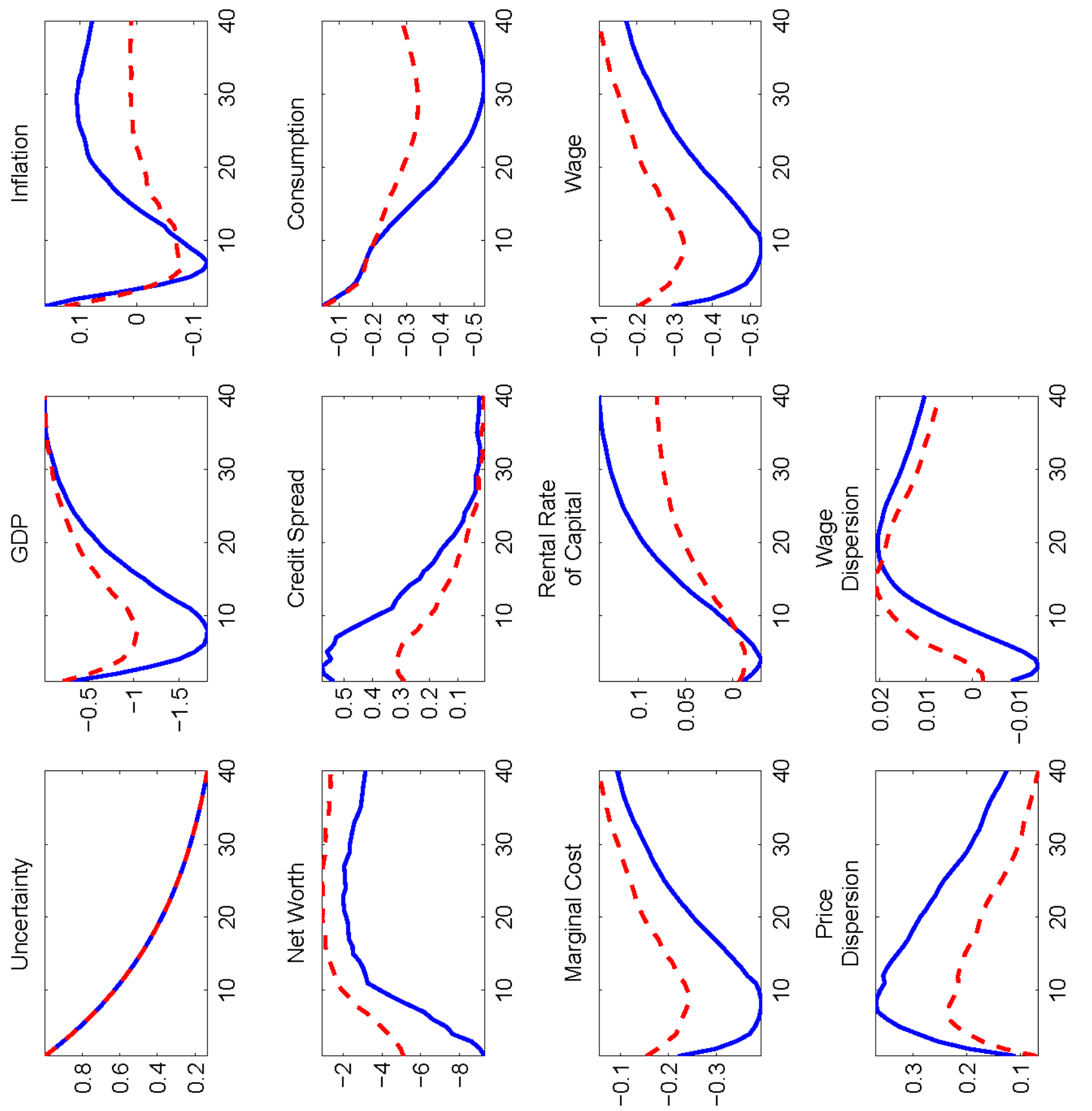

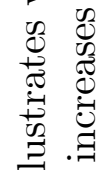

$.70^{2}$

ఫ્ఠ

$=$

몽

횽

\&0

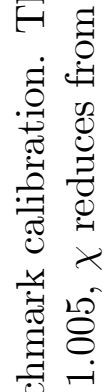

넝

.00

융

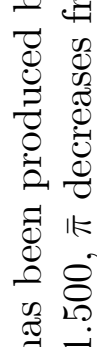

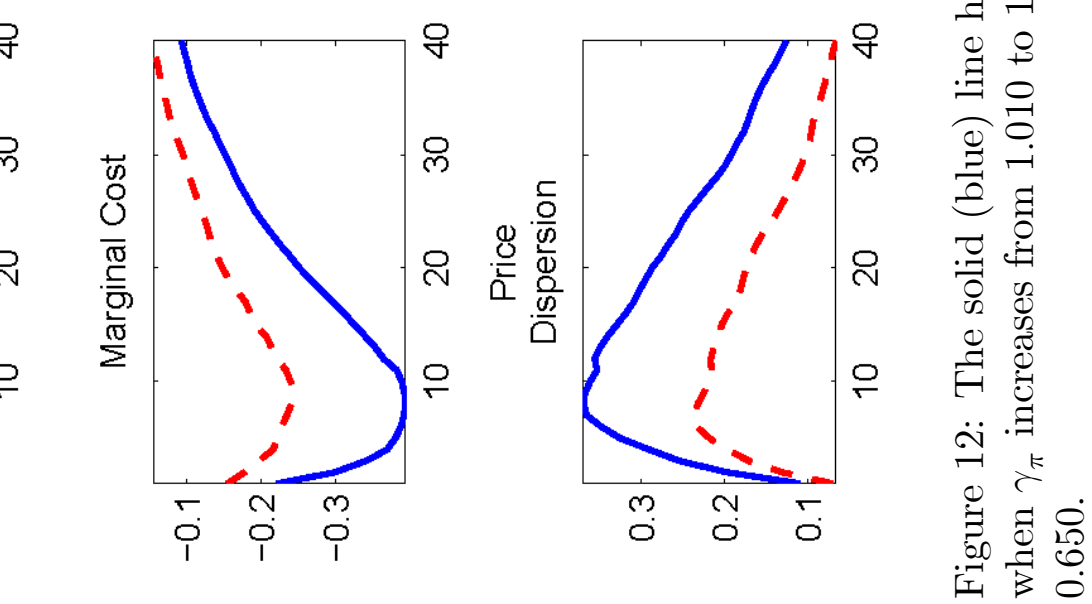




\subsubsection{Flexible Wages or prices}

Next we study the effects on the economy after an uncertainty shock when nominal wages are not subject to frictions (Figure 9 ). This simulation assumes that the Calvo probability of resetting wages $\theta_{w}$ and the wage indexation parameter $\chi_{w}$ decrease from 0.700 and 0.800 to 0.05 and 0 , respectively. Relative to the benchmark case we see that flexible wages do not lead to large changes in the impact of uncertainty on aggregate demand. Agents in the flexible wage case respond by supplying more labour causing wages to fall by more. This turns out to have an impact on the marginal cost and inflation as they fall in the first two years by more in the flexible wage case. However, the pricing bias channel is still present-inflation does not fall as much as the marginal cost and after two years inflation response closely tracks the benchmark inflation profile. This implies positive policy rates for a large period that offset the majority of the short lasting stimulus (via negative short term rates) and explain why demand contracts by a very similar amount under both scenarios.

Following Christiano et al. (2010) we investigate the economic effects after an uncertainty shock when prices are able to adjust freely (Figure 10) - the Calvo probability $\theta_{p}$ and indexation $\chi$ decrease from 0.550 and 0.400 to 0.05 and 0 , respectively. Although the effects on (aggregate) demand and prices appear to be very similar to the flexible wages case, the transmission mechanism is very different. With flexible prices, the prices Phillips curve drops from the system and real wages equal zero for all $t$. Thus price inflation becomes a function of the nominal wage inflation and not a function of the marginal cost. Given that real wages equal zero for all $t$, nominal wage inflation is just a function of the real marginal cost of work (namely consumption and labour demand) which is falling.

The change in real activity response implied by these simulations is consistent with what we 
find using the FAVAR model. Note, however, that these experiments suggest that an increase in wage or price flexibility has little impact on the magnitude of the credit spread response and leads to a change in the inflation response. The time-varying FAVAR responses offer little evidence to support these latter changes.

\subsubsection{Financial liberalisation}

In this simulation we assume that the asymmetry between borrower and lender has been reduced (Figure 11) - the entrepreneur auditing cost $\mu_{E}$ and the annual credit steady state spread decreases from 0.210 and 300bps to 0.05 and 50bps, respectively. After this change in these parameters, an uncertainty shock has almost no effect on credit spreads and net-worth. This is due to the low value of entrepreneur auditing cost $\left(\mu_{E}=0\right.$ implies no asymmetry between borrowers and lenders). As a consequence, investment does not collapse in this case as agents face a tiny external finance premium. Note also that the dynamics of inflation and the policy rate are quite different under financial liberalisation and this feature does not match the FAVAR results.

\subsection{Discussion}

The simulations presented above indicate that the estimated changes in the response of real activity and credit spreads to uncertainty shocks can be consistent with a shift in Taylor rule parameters, wage/price rigidity and easing of financial frictions. In contrast, it seems harder to replicate closely the empirical result that the response of inflation and the short-term rate has been stable over time. Comparing figures 8 to 11 , it appears that one can get closest to the empirical results by increasing $\gamma_{\pi}$ from 1.010 to 1.500. While, the increase in the Federal Reserve's anti-inflationary stance after the mid-1980s has been documented and supported by several studies (see Lubik and Schorfheide (2004)), it seems reasonable to suppose that the US economy has been subject to other 
structural changes at the same time. For example, using a time-varying DSGE model, FernandezVillaverde and Rubio-Ramirez (2008) provide evidence for a decrease in the inflation target and the 'flattening' of the Phillips curve on top of an increase in the Taylor rule inflation coefficient.

In figure 12 we consider changes in a number of parameters that match the findings of FernandezVillaverde and Rubio-Ramirez (2008). In particular, this figure compares the benchmark impulse responses from those obtained under the scenario where monetary authorities fight inflation more aggressively $\left(\gamma_{\pi}\right.$ increases from 1.010 to 1.500$)$, the steady-state inflation is reduced $(\bar{\pi}$ decreases from $4 \%$ to $2 \%$ ), firm rely less on indexation rules of thumb ( $\chi$ reduces from 0.400 to 0.100 ) and reset prices less frequently due to price stability ( $\theta_{p}$ increases from 0.550 to 0.650$)$. Figure 12 shows that the changes in the impulse responses are close to the empirical results. Under the alternative scenario, the response of real activity and spreads to the uncertainty shocks is weaker. However, the response of inflation and the short-term interest rate is fairly similar, especially at short and medium term horizons. The increase in price stickiness and a decrease in indexation has an upward effect on the pricing bias which counteracts the decrease in this channel induced by the rise in $\gamma_{\pi}$. With inflation closer to a lower target, firms find it optimal not to rest prices very often. However, this reduction in price re-setting leads them to account more for the risk of being locked in a contractual agreement to supply goods at a price lower than the aggregate price.

In contrast, a combination of financial liberalisation and changes in the Phillips curve parameters outlined above would lead to large changes in the inflation and the interest rate response. Notice from figure 11 that as financial frictions ease, the response of inflation to uncertainty shock is larger in magnitude. This channel is further magnified with a fall in indexation and an increase in price stickiness.

Therefore, a change in Taylor rule and Phillips curve parameters provides a candidate expla- 
nation for the temporal shift in the responses estimated using the FAVAR model. As noted above, the fact that the change in these model parameters has been reported by other studies provides an argument for believing this explanation to be a plausible one.

\section{Conclusions}

This paper considers whether the impact of uncertainty shocks on the US economy has changed over time. Using an extended FAVAR model that allows the estimation of the time-varying impact of uncertainty shocks we find that the response of real activity series such as GDP growth and financial series such as the BAA credit spread to this shock has declined over time. In contrast, the estimated response of inflation and short-term interest rates has remained fairly constant over time. We use a non-linear DSGE model with stochastic volatility to gauge the possible factors behind these changes. The DSGE simulations suggest that the empirical results can be closely replicated when we incorporate an increase in the monetary authorities anti-inflation stance and simultaneously allow the degree of price stickiness to rise and indexation to fall. This highlights the importance of monetary policy and inflation dynamics in determining the role played by uncertainty and the importance of this shock for economic fluctuations.

\section{References}

Alessandri, Piergiorgio and Haroon Mumtaz, 2014, Financial Regimes and Uncertainty Shocks, Working Papers 729, Queen Mary University of London, School of Economics and Finance.

Aruoba, Boragan, Luigi Bocola and Frank Schorfheide, 2011, A New Class of Nonlinear Times Series Models for the Evaluation of DSGE Models, In progress. 
Asai, Manabu and Michael McAleer, 2009, Multivariate stochastic volatility, leverage and news impact surfaces, Econometrics Journal 12(2), 292-309.

Basu, Susanto and Brent Bundick, 2011, Uncertainty Shocks in a Model of Effective Demand, Boston College Working Papers in Economics 774, Boston College Department of Economics.

Beetsma, Roel and Massimo Giuliodori, 2012, The changing macroeconomic response to stock market volatility shocks, Journal of Macroeconomics 34(2), $281-293$.

Benati, Luca, 2014, Economic Policy Uncertainty and the great recession, mimeo, University of Bern.

Benati, Luca and Haroon Mumtaz, 2007, U.S. evolving macroeconomic dynamics - a structural investigation, Working Paper Series 746, European Central Bank.

Bernanke, B. S., J. Boivin and P. Eliasz, 2005, Measuring the Effects of Monetary Policy: A Factor Augmented Vector Autoregressive (FAVAR) Approach, Quarterly Journal of Economics 120, 387-422.

Bernanke, Ben S., Mark Gertler and Simon Gilchrist, 1999, The financial accelerator in a quantitative business cycle framework, in J. B. Taylor and M. Woodford (editors), Handbook of Macroeconomics, Vol. 1 of Handbook of Macroeconomics, chapter 21, pp. 1341-1393.

Berument, Hakan, Yeliz Yalcin and Julide Yildirim, 2009, The effect of inflation uncertainty on inflation: stochastic volatility in mean model within a dynamic framework, Economic Modelling $\mathbf{2 6}(6), 1,201-07$.

Bloom, Nicholas, 2009, The Impact of Uncertainty Shocks, Econometrica 77(3), 623-85. 
Caggiano, Giovanni, Efrem Castelnuovo and Nicolas Groshenny, 2014, Uncertainty shocks and unemployment dynamics in U.S. recessions, Journal of Monetary Economics 67(0), 78 - 92.

Canova, Fabio and Luca Sala, 2009, Back to square one: Identification issues in $\{$ DSGE\} models, Journal of Monetary Economics 56(4), 431 - 449.

Carlin, Bradley P., Nicholas G. Polson and David S. Stoffer, 1992, A Monte Carlo Approach to Nonnormal and Nonlinear State-Space Modeling, Journal of the American Statistical Association 87(418), 493-500.

Carriero, Andrea, Todd E. Clark and Massimiliano Marcellino, 0, Common Drifting Volatility in Large Bayesian VARs, Journal of Business $\&$ Economic Statistics 0(ja), 00-00.

Carter, C and P Kohn, 2004, On Gibbs sampling for state space models, Biometrika 81, 541-53.

Choi, Sangyup, 2013, Are the effects of BloomŠs uncertainty shocks robust?, Economics Letters $\mathbf{1 1 9}(2), 216-220$.

Christiano, Lawrence, Cosmin L. Ilut, Roberto Motto and Massimo Rostagno, 2010, Monetary Policy and Stock Market Booms, NBER Working Papers 16402, National Bureau of Economic Research, Inc.

Christiano, Lawrence, Martin Eichenbaum and Charles Evans, 2005, Nominal Rigidities and the Dynamic Effects of a shock to Monetary Policy, Journal of Political Economy 113, 1-45.

Christiano, Lawrence, Roberto Motto and Massimo Rostagno, 2014, Risk Shocks, American Economic Review 104(1), 27-65.

Cogley, T. and T. J. Sargent, 2005, Drifts and Volatilities: monetary policies and outcomes in the Post WWII U.S., Review of Economic Dynamics 8, 262-302. 
Davig, Troy and Eric M. Leeper, 2007, Generalizing the Taylor Principle, American Economic Review 97(3), 607-635.

Delnegro, Marco and Christopher Otrok, 2005, Dynamic factor models with time-varying parameters, Mimeo, Federal Reserve Bank of Atlanta.

Fernandez-Villaverde, Jesus and Juan F. Rubio-Ramirez, 2008, How Structural Are Structural Parameters?, NBER Macroeconomics Annual 200\%, Volume 22, NBER Chapters, National Bureau of Economic Research, Inc, pp. 83-137.

Fernandez-Villaverde, Jesus, Pablo Guerron-Quintana, Juan F. Rubio-Ramirez and Martin Uribe, 2011, Risk Matters: The Real Effects of Volatility Shocks, American Economic Review 101(6), 2530-61.

Fernández-Villaverde, Jesús, Pablo A. Guerrón-Quintana, Keith Kuester and Juan Rubio-Ramírez, 2011, Fiscal Volatility Shocks and Economic Activity, NBER Working Papers 17317, National Bureau of Economic Research, Inc.

Friedman, Benjamin M., 2005, What Remains from the Volcker Experiment?, Working Paper 11346, National Bureau of Economic Research.

Hofmann, Boris, Gert Peersman and Roland Straub, 2012, Time variation in U.S. wage dynamics, Journal of Monetary Economics 59(8), 769-783.

Jacquier, E, N Polson and P Rossi, 1994, Bayesian analysis of stochastic volatility models, Journal of Business and Economic Statistics 12, 371-418.

Jurado, Kyle, Sydney C. Ludvigson and Serena Ng, 2013, Measuring Uncertainty, NBER Working Papers 19456, National Bureau of Economic Research, Inc. 
Koop, Gary and Simon M. Potter, 2011, Time varying \{VARs\} with inequality restrictions, Journal of Economic Dynamics and Control 35(7), 1126 - 1138.

Koopman, Siem Jan and Eugenie Hol Uspensky, 2000, The Stochastic Volatility in Mean Model, Tinbergen Institute Discussion Paper 00-024/4, Tinbergen Institute.

Kwiatkowski, Lukasz, 2010, Markov Switching In-Mean Effect. Bayesian Analysis in Stochastic Volatility Framework, Central European Journal of Economic Modelling and Econometrics 2(1), 59-94.

Lemoine, M. and C. Mougin, 2010, The Growth-Volatility Relationship: new Evidence Based on Stochastic Volatility in Mean Models, Working Paper 285, Banque de France.

Lubik, Thomas A. and Frank Schorfheide, 2004, Testing for Indeterminacy: An Application to U.S. Monetary Policy, American Economic Review 94(1), 190-217.

Mumtaz, Haroon and Konstantinos Theodoridis, n.d., The international transmission of volatility shocks: an empirical analysis, Journal of European Economic Association .

Primiceri, G, 2005, Time varying structural vector autoregressions and monetary policy, The Review of Economic Studies 72(3), 821-52.

Smets, Frank and Rafael Wouters, 2007, Shocks and Frictions in US Business Cycles: a Bayesian DSGE Approach, American Economic Review 97, 586-606.

Spiegelhalter, David J., Nicola G. Best, Bradley P. Carlin and Angelika Van Der Linde, 2002, Bayesian measures of model complexity and fit, Journal of the Royal Statistical Society: Series $B$ (Statistical Methodology) 64(4), 583-639. 
Stock, James H. and Mark W. Watson, 2012, Generalized Shrinkage Methods for Forecasting Using Many Predictors, Journal of Business $\&$ Economic Statistics 30(4), 481-493.

Watson, Mark W., 2014, Inflation Persistence, the NAIRU, and the Great Recession, American Economic Review 104(5), 31-36. 